\title{
A linear method for the retrieval of sun-induced chlorophyll fluorescence from GOME-2 and SCIAMACHY data
}

\author{
P. Köhler ${ }^{1,2}$, L. Guanter ${ }^{1,2}$, and J. Joiner ${ }^{3}$ \\ ${ }^{1}$ Institute for Space Sciences, Freie Universität Berlin, Berlin, Germany \\ ${ }^{2}$ German Research Center for Geosciences (GFZ), Remote Sensing Section, Potsdam, Germany \\ ${ }^{3}$ NASA Goddard Space Flight Center, Greenbelt, MD, USA \\ Correspondence to: P. Köhler (philipp.koehler@gfz-potsdam.de)
}

Received: 12 September 2014 - Published in Atmos. Meas. Tech. Discuss.: 4 December 2014

Revised: 3 June 2015 - Accepted: 4 June 2015 - Published: 26 June 2015

\begin{abstract}
Global retrievals of near-infrared sun-induced chlorophyll fluorescence (SIF) have been achieved in the last few years by means of a number of space-borne atmospheric spectrometers. Here, we present a new retrieval method for medium spectral resolution instruments such as the Global Ozone Monitoring Experiment-2 (GOME-2) and the SCanning Imaging Absorption SpectroMeter for Atmospheric CHartographY (SCIAMACHY). Building upon the previous work by Guanter et al. (2013) and Joiner et al. (2013), our approach provides a solution for the selection of the number of free parameters. In particular, a backward elimination algorithm is applied to optimize the number of coefficients to fit, which reduces also the retrieval noise and selects the number of state vector elements automatically. A sensitivity analysis with simulated spectra has been utilized to evaluate the performance of our retrieval approach. The method has also been applied to estimate SIF at $740 \mathrm{~nm}$ from real spectra from GOME-2 and for the first time, from SCIAMACHY. We find a good correspondence of the absolute SIF values and the spatial patterns from the two sensors, which suggests the robustness of the proposed retrieval method. In addition, we compare our results to existing SIF data sets, examine uncertainties and use our GOME-2 retrievals to show empirically the relatively low sensitivity of the SIF retrieval to cloud contamination.
\end{abstract}

\section{Introduction}

During the process of photosynthesis, the chlorophyll- $a$ of photosynthetically active vegetation emits a small fraction of its absorbed energy as an electromagnetic signal (e.g., Zarco-
Tejada et al., 2003). This signal, called sun-induced fluorescence (SIF), takes place in the $650-800 \mathrm{~nm}$ spectral region. Several studies have addressed the estimation of SIF from ground-based, airborne and spaceborne spectrometers in the last decade (see Meroni et al., 2009, and references therein). Here, we focus on SIF retrieval methods from space and their achievements.

The first global SIF observations have been achieved in the last 4 years by studies from Joiner et al. (2011), Frankenberg et al. (2011a) and Guanter et al. (2012) using data from the Fourier transform spectrometer (FTS) on board the Japanese Greenhouse Gases Observing Satellite (GOSAT). The first band of the GOSAT-FTS samples the 755-775 nm spectral window with a high spectral resolution of approximately $0.025 \mathrm{~nm}$, which enabled an evaluation of the in-filling of solar Fraunhofer lines around the $\mathrm{O}_{2} \mathrm{~A}$ absorption band by SIF. Joiner et al. (2011) based their retrieval on the strong K line around $770.1 \mathrm{~nm}$ on condition that a measured irradiance spectrum is available. In contrast, Frankenberg et al. (2011b) and Guanter et al. (2012) used two micro fitting windows around 757 and $770 \mathrm{~nm}$ by means of a reference solar irradiance data set. The $757 \mathrm{~nm}$ spectral region contains several solar Fraunhofer lines and is devoid of significant atmospheric absorption, which minimizes the impact of atmospheric effects on the retrieval. Two micro fitting windows have also been used by Joiner et al. (2012) to reduce noise, whereas SIF-free Earth radiance spectra served as a reference. The method proposed by Frankenberg et al. (2011a) relies on the physical modeling of the in-filling of several solar Fraunhofer lines by SIF using the instrumental line shape function and a reference solar irradiance data set. The surface re- 
flectance, atmospheric scattering as well as wavelength shifts have to be estimated for each measurement. Instead of explicitly modeling these parameters for each measurement, Guanter et al. (2012) proposed a data-driven approach, which is based on a singular value decomposition (SVD) technique. The basic assumption for this retrieval method is that any radiance spectrum can be expressed as a linear combination of singular vectors plus fluorescence. A caveat of this technique is an arbitrary selection of the optimum number of singular vectors, which has an effect on the retrieval accuracy and precision.

One intrinsic limitation of the GOSAT-FTS data arises from the coarse resolution of global maps $\left(2^{\circ} \times 2^{\circ}\right)$, which is caused by a poor spatial sampling and a relatively high retrieval noise (Frankenberg et al., 2011b). Therefore, it was crucial that results from Joiner et al. (2012, 2013) indicated that instruments with lower spectral resolutions but better spatial coverage are also capable of estimating SIF from space. Joiner et al. (2012) examined the in-filling of the deep calcium (Ca) II solar Fraunhofer line at $866 \mathrm{~nm}$ by SIF using the SCanning Imaging Absorption SpectroMeter for Atmospheric CHartographY (SCIAMACHY) satellite instruments, which has a spectral resolution of approximately $0.5 \mathrm{~nm}$. Spatial and temporal variations of retrieved SIF were found to be consistent, although there is only a weak intensity of SIF in the examined spectral range. In this context, it should be considered that the representativeness of spatially mapped SIF is enhanced by using data from instruments which provide a continuous spatial sampling.

A further achievement was the data-driven study of Joiner et al. (2013). They proposed another SIF retrieval method for the Global Ozone Monitoring Experiment-2 (GOME-2), which enabled a significant increase of the spatiotemporal resolution with respect to previous works. In principle, this proposed approach extends the SVD (or principal component analysis, PCA) technique applied exclusively on solar Fraunhofer lines (Guanter et al., 2012) to a broader wavelength range making also use of atmospheric absorption bands (water vapor, $\mathrm{O}_{2} \mathrm{~A}$ ).

Here, we present a new SIF retrieval method using a comparable methodology to that developed for ground-based instrumentations by Guanter et al. (2013) and for spacebased measurements by Joiner et al. (2013). A feature of the method is the automated determination of the principal components (PCs) needed. The proposed retrieval method is applied to simulated data (Sect. 4) as well as to data from GOME-2 and SCIAMACHY (Sect. 5). Besides a time series of GOME-2 SIF covering the 2007-2011 time period, we are able to present a SIF data set from SCIAMACHY data for the August 2002-March 2012 time span. We compare those data sets with each other (Sect. 5.3) and with existing SIF data sets from GOME-2 (Joiner et al., 2013) and GOSAT data (Köhler et al., 2015) (Sect. 5.4). In addition, we examine uncertainties (Sects. 5.5, 5.6) and assess the effect of clouds on the

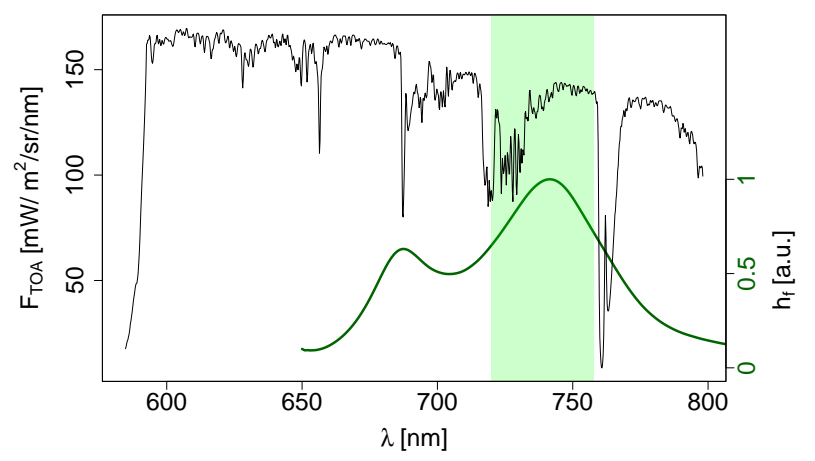

Figure 1. Sample GOME-2 spectrum in band 4. The spectral window that we use for SIF retrievals $(720-758 \mathrm{~nm})$ is marked in green. The reference fluorescence emission spectrum is depicted in green.

retrieval through the analysis of different cloud filter thresholds (Sect. 5.7).

\section{Instruments}

\subsection{GOME-2}

The Global Ozone Monitoring Experiment-2 (Munro et al., 2006) is a nadir-scanning medium-resolution UV/VIS spectrometer on board EUMETSAT's polar orbiting Meteorological Operational Satellites (MetOp-A and MetOpB). MetOp-A (launched in October 2006) and MetOp-B (launched in September 2012) each carry 13 instruments performing operational measurements of atmosphere, land and sea surface. The polar orbit satellites reside in orbit at an altitude of approximately $820 \mathrm{~km}$ and have an equator crossing time near 09:30 local solar time. One revolution takes around $100 \mathrm{~min}$. GOME-2 was designed to measure distributions of various chemical trace gases in the atmosphere. For this purpose, the spectral range between 240 and $790 \mathrm{~nm}$ is covered by four detector channels. The fourth channel (590$790 \mathrm{~nm}$ ) encompasses the SIF wavelength region (Fig. 1). This channel has a spectral resolution of $0.5 \mathrm{~nm}$ and a signalto-noise ratio (SNR) up to 2000. Here, we use a subchannel from GOME-2 on board MetOp-A, namely the spectral region between 720 and $758 \mathrm{~nm}$ covering 191 spectral points, to evaluate the SIF at $740 \mathrm{~nm}$. The large default swath width of $1920 \mathrm{~km}$ with a footprint size of $80 \mathrm{~km} \times 40 \mathrm{~km}$ enables a global coverage within 1.5 days. The GOME-2 level 1B product consists of radiance spectra and a daily solar irradiance measurement. Satellite data covering the 2007-2011 time period were used for this study.

\subsection{SCIAMACHY}

SCIAMACHY (Bovensmann et al., 1999) was 1 of 10 instruments on board European Space Agency's Environmental Satellite (ENVISAT). ENVISAT was launched in March 
2002 and became non-operational in April 2012, when communications were lost. Similar to MetOp-A, the satellite has a sun-synchronous orbit at an altitude of approximately $800 \mathrm{~km}$ with an equator overpass time at 10:00 local solar time. Like GOME-2, the SCIAMACHY instrument was designed to measure distributions of various chemical trace gases in the atmosphere. Overall, a spectral range of 240$2400 \mathrm{~nm}$ is covered by eight detector channels, whereas a subset of the fourth channel $(604-805 \mathrm{~nm}$, spectral resolution of $0.48 \mathrm{~nm}$, SNR up to 3000 ) is used to evaluate the amount of SIF at $740 \mathrm{~nm}$.

SCIAMACHY measured alternately in nadir and limb mode, which leads to blockwise rather than continuous nadir measurements. Due to this default scan option, a global coverage is achieved within 6 days. The swath width of $960 \mathrm{~km}$ is only half as large as the swath width of GOME- 2 in the nominal mode while the spatial resolution along track is $30 \mathrm{~km}$ and the nominal across track pixel size is $60 \mathrm{~km}$. Due to data rate limitations, radiances in the spectral range of interest were downlinked at $240 \mathrm{~km}$ (four pixels binned) across track. Using the spectral interval between $720-758 \mathrm{~nm}$ to retrieve SIF leads therefore to a reduced spatial resolution by a factor of 2-3 compared to GOME-2.

As stated in Lichtenberg et al. (2006), two relevant corrections have to be applied in the processing chain of the level 1 data for the considered wavelength range: the memory effect correction and the dark signal correction. The first correction is probably more critical and a potential error source in the SIF retrieval because the memory effect modifies the absolute value of the signal and it involves the risk of artificial spectral features in the measurements. Both changes produce artifacts that are expected to influence SIF retrieval results since the level of SIF in comparison to the total signal at the sensor is low. Satellite data of SCIAMACHY for the August 2002-March 2012 time span have been used for this study.

\section{Retrieval methodology}

The main challenge when retrieving SIF from space-borne instruments is to isolate the SIF signal from the about 100-times-more-intense reflected solar radiation in the measured top-of-atmosphere (TOA) radiance spectrum. This section describes a strategy which is similar to the data-driven method proposed by Joiner et al. (2013).

\subsection{Fundamental basis}

Assuming a Lambertian reflecting surface in a plane-parallel atmosphere, the TOA radiance measured by a satellite sensor $\left(\boldsymbol{F}_{\mathrm{TOA}}\right)$ can be described by:

$\boldsymbol{F}_{\mathrm{TOA}}=\frac{\boldsymbol{\rho}_{\mathrm{p}}}{\pi} \cdot \boldsymbol{I}_{\mathrm{sol}} \cdot \mu_{0}$, where $\boldsymbol{\rho}_{\mathrm{p}}$ is the planetary reflectance, $\boldsymbol{I}_{\mathrm{sol}}$ is the solar irradiance at the TOA and $\mu_{0}$ is the cosine of the solar zenith angle (bold characters indicate variables with a spectral component). Verhoef and Bach (2003) split $\rho_{\mathrm{p}}$ into contributions due to atmospheric path radiance, adjacency effect (path radiance from objects outside the field of view), reflected skylight by the target and reflected sunlight by the target. Assuming that a fluorescent target is observed, Eq. (1) can be modified as follows

$\boldsymbol{F}_{\mathrm{TOA}}=\frac{\boldsymbol{\rho}_{\mathrm{p}}}{\pi} \cdot \boldsymbol{I}_{\mathrm{sol}} \cdot \mu_{0}+F_{\mathrm{S}} \cdot \boldsymbol{h}_{\mathrm{f}} \cdot \boldsymbol{T}_{\uparrow}$,

where $F_{\mathrm{s}}$ is the amount of sun-induced fluorescence at $740 \mathrm{~nm}$ (second peak of the emission spectrum), $\boldsymbol{h}_{\mathrm{f}}$ is a normalized reference fluorescence emission spectrum and $\boldsymbol{T}_{\uparrow}$ is the atmospheric transmittance in the upward direction.

As stated above, we use a statistical modeling approach similar to Joiner et al. (2013) in order to separate spectral features from planetary reflectance (including atmospheric absorption, atmospheric path radiance, surface reflectance) and SIF. The basic idea consists of modeling low and high frequency components of the planetary reflected radiance with a sufficient accuracy to be able to evaluate the changes in the fractional depth of solar Fraunhofer lines by SIF. It has to be emphasized that the main information for the retrieval is expected to originate from solar Fraunhofer lines, as simulations with a flat solar spectrum (Joiner et al., 2013) have shown that essentially no information about SIF can be retrieved. More specifically, it was not possible to disentangle atmospheric absorption from the SIF signal in the $\mathrm{O}_{2}$ A-band with the statistical approach.

Here, $\boldsymbol{I}_{\text {sol }}$ is known through satellite measurements (from GOME-2 and SCIAMACHY) or the external spectral library from Chance and Kurucz (2010), which has been used for the sensitivity analysis. Since $\boldsymbol{h}_{\mathrm{f}}$ is a prescribed spectral function, it is necessary to find appropriate estimates for $\boldsymbol{\rho}_{\mathrm{p}}$ and $\boldsymbol{T}_{\uparrow}$ to retrieve the amount of SIF at $740 \mathrm{~nm}\left(F_{\mathrm{S}}\right)$. In order to model $\rho_{\mathrm{p}}$ with a high accuracy, we use a combination of a thirdorder polynomial in wavelength to account for the spectrally smooth part and a set of atmospheric principal components (PCs) for the high frequency pattern of the spectrum. Thus, the preliminary forward model can be written as

$\boldsymbol{F}_{\mathrm{TOA}}=\boldsymbol{I}_{\mathrm{sol}} \cdot \frac{\mu_{0}}{\pi} \cdot \sum_{i=0}^{3}\left(\alpha_{i} \cdot \lambda^{i}\right) \cdot \sum_{j=1}^{n_{\mathrm{PC}}}\left(\beta_{j} \cdot \boldsymbol{P} \boldsymbol{C}_{j}\right)+F_{\mathrm{s}} \cdot \boldsymbol{h}_{\mathrm{f}} \cdot \boldsymbol{T}_{\uparrow}$,

where $\alpha_{i}, \beta_{j}, F_{\mathrm{S}}$ and $\boldsymbol{T}_{\uparrow}$ are the unknowns which are necessary to generate a synthetic measurement. Note that Eq. (3) is equivalent to the forward model from Joiner et al. (2013) and Guanter et al. (2015). The difference lies in the derivation and interpretation, since so far no assumptions concerning effects of atmospheric scattering were made. The spectrally smooth contribution can mostly be attributed to surface reflectance and atmospheric scattering effects, which is henceforth referred to as apparent reflectance. The spectrally oscillating 
part is due to distinct atmospheric absorption features. Although the continuum absorption of the atmosphere is part of the apparent reflectance (low frequency component), we formally refer to the oscillating component of the spectrum as effective atmospheric transmittance.

The statistically based approach assumes that spectra without SIF emission can reproduce the variance of the planetary reflectance also for spectra which contain SIF. For this purpose, the data are divided into a training set (measurements over non-fluorescent targets) and a test set (basically all measurements over land). According to Eq. (3), spectra of the training set need to be disaggregated into low and high frequency components in order to generate atmospheric PCs as described below.

\subsection{Preparation of training set and generation of atmospheric principal components}

The training set is exclusively composed of measurements over non-fluorescent targets and we assume that Eq. (2) is valid. As in Joiner et al. (2013), we use a principal component analysis (PCA) to convert these SIF-free spectra into a set of linearly uncorrelated components (PCs). Only a subset of all PCs (the same number as spectral points in the fitting window) will be needed to reconstruct each SIF-free spectrum with an appropriate precision.

First of all, $\rho_{\mathrm{p}}$ is obtained through the normalization of the spectrum by the solar irradiance $\left(\boldsymbol{I}_{\mathrm{sol}}\right)$ (which is also measured by GOME-2/SCIAMACHY), the cosine of the solar zenith angle $\left(\mu_{0}\right)$ and $\pi$. Figure 2 depicts such a normalized sample GOME-2 measurement in the $720-758 \mathrm{~nm}$ fitting window. The next step requires an estimate of the apparent reflectance (or the spectrally smooth component). Therefore, we assume two windows mostly devoid of atmospheric absorption within the retrieval window, namely the spectral regions between $721.5-722.5$ and $743-758 \mathrm{~nm}$, in order to estimate the apparent reflectance by a third-order polynomial. This is also shown in Fig. 2.

In the next step, the apparent reflectance estimate is used to normalize $\rho_{\mathrm{p}}$ in order to separate the effective atmospheric transmittance (high frequency component). If all spectra from the training set are processed in this way, a PCA is applied in order to obtain the atmospheric PCs. It is necessary to capture a sufficient number of atmospheric states within the training set so that the effective atmospheric transmittance can also be adequately constructed for the test data. Effects of correlation between the PCs and SIF will be investigated in detail below (Sect. 4.3).

An important advantage in using this method is that there is no need to perform explicit radiative transfer calculations to characterize atmospheric parameters, which affect the measurement (e.g., temperature and water vapor profiles).

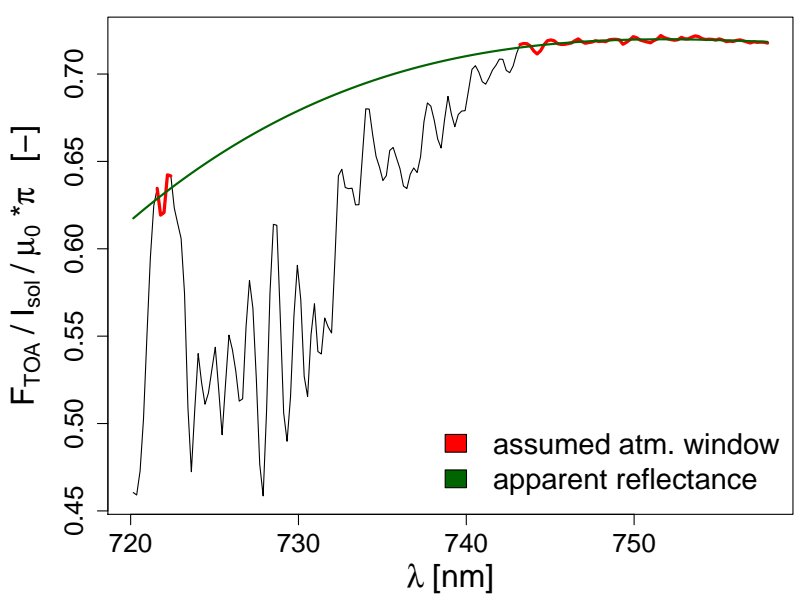

Figure 2. Estimation of apparent reflectance (green) from a sample GOME-2 measurement in the $720-758 \mathrm{~nm}$ fitting window by a third-order polynomial using atmospheric windows (red).

\subsection{Estimation of the ground to sensor transmittance}

According to the preliminary forward model in Eq. (3), an estimate of $\boldsymbol{T}_{\uparrow}$ is the last necessary step to be able to retrieve SIF.

As it was shown by Joiner et al. (2013), $\boldsymbol{T}_{\uparrow}$ can be approximated in terms of the total atmospheric transmittance in downward and upward direction $\left(\boldsymbol{T}_{\downarrow \uparrow}\right)$. Hence, $\boldsymbol{T}_{\downarrow \uparrow}$ and $\boldsymbol{T}_{\uparrow}$ are simultaneously computed from the state vector elements in the forward model from Joiner et al. (2013). Here, we estimate an effective ground to sensor transmittance $\left(\boldsymbol{T}_{\uparrow}^{\mathrm{e}}\right)$ prior to solving the forward model in order to obtain an additional model parameter. The equation relating $\boldsymbol{T}_{\uparrow}^{\mathrm{e}}$ to $\boldsymbol{T}_{\downarrow \uparrow}^{\mathrm{e}}$ is given by

$\boldsymbol{T}_{\uparrow}^{\mathrm{e}}=\exp \left[\ln \left(\boldsymbol{T}_{\downarrow \uparrow}^{\mathrm{e}}\right) \cdot \frac{\sec \left(\theta_{\mathrm{v}}\right)}{\sec \left(\theta_{\mathrm{v}}\right)+\sec \left(\theta_{0}\right)}\right]$,

where $\theta_{\mathrm{v}}$ is the viewing zenith angle and $\theta_{0}$ is the solar zenith angle. Each measurement is normalized in the same way as for the training set to separate $\boldsymbol{T}_{\downarrow \uparrow}^{\mathrm{e}}$, that is in turn used to estimate $\boldsymbol{T}_{\uparrow}^{\mathrm{e}}$ through Eq. (4). Figure 3 depicts such an estimation for a sample GOME-2 measurement.

However, a few implications arise through this approach, which are evaluated in the following.

Firstly, it is necessary to assume zero SIF, although these measurements potentially contain a SIF emission. Hence, an in-filling of atmospheric absorption lines might occur, which potentially affects the estimation of $\boldsymbol{T}_{\uparrow}^{\mathrm{e}}$ and in turn the retrieved SIF. By means of simulated TOA radiances (a detailed description can be found in Sect. 4), it becomes apparent that this effect is negligible. We have tested two scenarios without instrumental noise, a medium and a large difference in SIF emission (2.1 and $4.3 \mathrm{~mW} \mathrm{~m}^{-2} \mathrm{sr}^{-1} \mathrm{~nm}^{-1}$ ), and calculated $\boldsymbol{T}_{\uparrow}^{\mathrm{e}}$. Figure 4 depicts the resulting changes in $\boldsymbol{T}_{\uparrow}^{\mathrm{e}}$ due to 


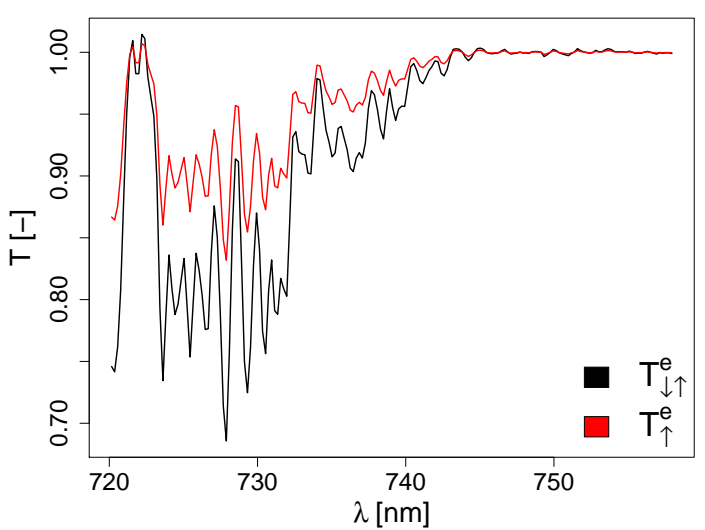

Figure 3. Estimation of the effective atmospheric transmittance in down- and upward direction (black) and in upward direction (red) using Eq. (4) from a sample GOME-2 measurement in the 720 $758 \mathrm{~nm}$ fitting window.

the in-filling of atmospheric absorption lines, and as can be seen, differences are only marginal.

Another consequence of the $\boldsymbol{T}_{\uparrow}^{\mathrm{e}}$ estimation procedure arises through the normalization of $\boldsymbol{T}_{\uparrow}^{\mathrm{e}}$ to one, although continuum absorption exists. This can lead to a bias in retrieved SIF values for inclined illumination/viewing angles and a high optical thickness (Guanter et al., 2015). It should also be noted, that the first assumed atmospheric microwindow $(721.5-722.5 \mathrm{~nm})$ might be influenced by water vapor absorption to a small extent, which is due to the instrumental resolution of about $0.5 \mathrm{~nm}$. In consequence, too high retrieval results may occur. However, the contribution of SIF in the lower wavelengths of the fitting window is decreased for two reasons: an increasing distance to the maximum of the prescribed spectral function at $740 \mathrm{~nm}$ and atmospheric absorption (except for the atmospheric microwindow). These theoretical considerations as well as our simulation results suggest that this effect is also negligible.

Our forward model is linearized as a result of the implementation from $\boldsymbol{T}_{\uparrow}^{\mathrm{e}}$ as a model parameter. That means the estimation problem could in principle be solved without iterations. However, it should be noted that the SIF estimation is inherently non-linear, and a linearisation is necessary, either at each step of an iterative algorithm (Joiner et al., 2013) or in advance.

\subsection{Final forward model}

By using $\boldsymbol{I}_{\mathrm{sol}}, \boldsymbol{\lambda}, \boldsymbol{P C}$ and $\boldsymbol{T}_{\uparrow}^{\mathrm{e}}$ as model parameters and merging the high and low frequency components to model the planetary reflectance, the final forward model results in

$\boldsymbol{F}_{\mathrm{TOA}}=\boldsymbol{I}_{\mathrm{sol}} \cdot \frac{\mu_{0}}{\pi} \cdot \sum_{i=0}^{3} \sum_{j=1}^{n_{\mathrm{PC}}}\left(\gamma_{i, j} \cdot \lambda^{i} \cdot \boldsymbol{P} \boldsymbol{C}_{j}\right)+F_{\mathrm{s}} \cdot \boldsymbol{h}_{\mathrm{f}} \cdot \boldsymbol{T}_{\uparrow}^{\mathrm{e}}$,

where $\gamma_{i, j}$ and $F_{\mathrm{s}}$ are the state vector elements. Thus, there are $4 \cdot n_{\mathrm{PC}}+1$ coefficients to be derived by an ordinary least

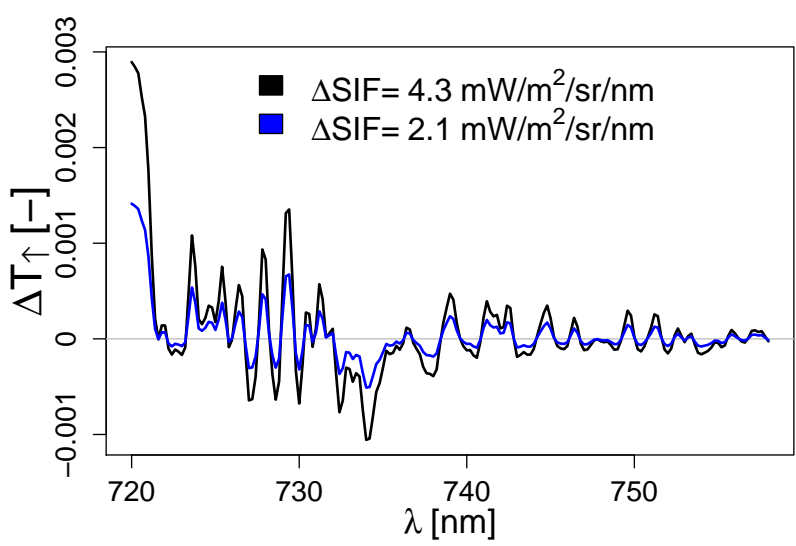

Figure 4. Changes in the estimated effective ground to sensor transmittance $\left(\boldsymbol{T}_{\uparrow}^{\mathrm{e}}\right)$ for a medium $\left(2.1 \mathrm{~mW} \mathrm{~m}^{-2} \mathrm{sr}^{-1} \mathrm{~nm}^{-1}\right.$, blue) and a large $\left(4.3 \mathrm{~mW} \mathrm{~m}^{-2} \mathrm{sr}^{-1} \mathrm{~nm}^{-1}\right.$, black) SIF emission difference. Simulated TOA radiances (described in Sect. 4) without instrumental noise have been used for the calculation of $\boldsymbol{T}_{\uparrow}^{\mathrm{e}}$ in the $720-758 \mathrm{~nm}$ fitting window.

squares fit. It might be noted that Eq. (5) is a simple algebraic transformation of Eq. (3).

A consequence of our approach is an increased number of state vector elements compared to Joiner et al. (2013), where the forward model is solved for $n_{\mathrm{i}}+n_{\mathrm{PC}}+1$ elements. Note that a comparable forward model to our approach was proposed by Guanter et al. (2013), where the forward model is further simplified by convolving only the most significant PC with the low order polynomial in wavelength to avoid an overfitting of the measurement. Here, we omit an overfitting by applying a backward elimination algorithm to reduce the number of coefficients to fit. An important and unique consequence, which arises through this additional step, is an automated determination of the optimum number of PCs. The selection of the number of PCs has an effect on retrieval accuracy and precision as it is known from studies by Guanter et al. (2013) and Joiner et al. (2013). Hence, it is crucial to provide a solution for this issue, which is described in the following.

\subsection{Backward elimination algorithm}

The forward model in Eq. (5) contains $4 \cdot n_{\mathrm{PC}}+1$ coefficients to fit, whereas not all of these coefficients are required. From a theoretical point of view, there is no reason to prefer an unnecessarily complex model rather than a simple one. To account for this fact, we use a backward elimination algorithm. Joiner et al. (2013) reported that only a few PCs (about 5, exact number depends on the fitting window) can explain already a very large amount of variance ( $>99.999 \%)$ of the normalized radiance. Using too many PCs and thus coefficients to fit might therefore result in an overfitting of the measurement. That means an unnecessarily complex model loses its predictive performance by fitting noise. For this reason, 
we start with all candidate variables and remove each variable in order to test if any removal improves the model fit to the data. It should be noted that the coefficients of the first PC (carrying the most variance) and the targeted SIF are excepted from being removed. If any removal improves the fit, the removed variable, which improves the model fit the most, is abandoned in the state vector from the forward model in Eq. (5). This process is repeated until no further improvement occurs (for each single retrieval). The improvement is determined through the Bayesian information criterion (BIC, Wit et al., 2012), formally defined as

$\mathrm{BIC}=-2 l(\widehat{\Theta})+p \cdot \log (n)$,

where $l(\widehat{\Theta})$ is the log-likelihood estimate of the model, $p$ is the number of model parameters and $n$ the number of spectral points. In simplified terms, it represents the goodness of fit weighted by the number of coefficients. The BIC is used as a statistical tool for model selection and balances the goodness of fit with the model complexity, where complexity refers to the number of parameters in the model. The BIC value itself is not interpretable, but the model with the lowest BIC should be preferred because a lower BIC is associated with fewer model parameters and/or a better fit.

It should be mentioned that there are also other methods to compare and select models in order to avoid problems of overfitted measurements. Here, we decided to use the BIC because it penalizes the number of model parameters the most. It should further be noted that it would be necessary to test all possible combinations of model parameters to find the "best" model, which is computationally too expensive. For this reason, a stepwise model selection (backward elimination) is performed.

Using the backward elimination algorithm has the consequence that the number of provided PCs is unimportant, as long as there are more PCs provided than actually necessary for an appropriate fit. In reverse it means that the optimum number of PCs is determined automatically. The detailed behavior of this supplementary step in comparison to a simple linear regression using all potential coefficients (all candidate variables) will be shown below in Sect. 4.3.

\subsection{Uncertainty estimation}

In order to assess the uncertainty of the SIF measurements, the $1 \sigma$ retrieval error is calculated by propagating the measurement noise. We assume that measurement noise can be characterized by spectrally uncorrelated Gaussian noise. In this case, following Sanders and de Haan (2013), the signalto-noise ratio (SNR) can be calculated for any radiance level if the SNR is known for a reference radiance level $F_{\text {ref }}$ at a reference wavelength $\lambda_{i}^{\text {ref }}$ following

$\operatorname{SNR}\left(\lambda_{i}\right)=\operatorname{SNR}_{\text {ref }} \cdot \sqrt{\frac{F\left(\lambda_{i}\right)}{F_{\text {ref }}}}$.
The measurement noise scales with the square root of the signal level, which is an appropriate assumption for grating spectrometers such as GOME-2 and SCIAMACHY. Here, we determine $\mathrm{SNR}_{\text {ref }}$ for each measurement (simulated and real) from the averaged radiance $\left(F_{\text {ref }}\right)$ from $757.7-758 \mathrm{~nm}$ using calculations of the SNR vs. level 1B calibrated radiances (also averaged from 757.7-758 nm) under defined conditions ( $2 \%$ albedo, solar zenith angle of $0^{\circ}$, integration time of $1.5 \mathrm{~s}$ ) performed by EUMETSAT. The error is then calculated through the evaluation of the retrieval error covariance matrix given by

$\mathbf{S}_{\mathrm{e}}=\left(\mathbf{K}^{\mathrm{T}} \mathbf{S}_{0}^{-1} \mathbf{K}\right)^{-1}$,

where $\mathbf{K}$ is the Jacobian matrix formed by linear model parameters from Eq. (3) and $\mathbf{S}_{0}$ is the measurement error covariance matrix, which is a diagonal matrix (because of the assumption of spectrally uncorrelated noise) with the elements

$\sigma_{i}^{2}=\left(\frac{F\left(\lambda_{i}\right)}{\operatorname{SNR}\left(\lambda_{i}\right)}\right)^{2}$

In order to assess the restriction for the precision of spatiotemporal SIF composites due to instrumental noise only, the standard error of the weighted average can be calculated for each grid cell by

$\sigma_{\text {noise }}\left(\overline{F_{\mathrm{s}}}\right)=\frac{1}{\sqrt{\sum_{i=1}^{n}\left(1 / \sigma_{i}\right)^{2}}}$,

where $\overline{F_{\mathrm{S}}}$ is the mean SIF value, and $\sigma_{i}$ is the $1 \sigma$ retrieval error given by Eq. (8).

Furthermore, the standard error of the mean from monthly mapped SIF has been computed for SCIAMACHY and GOME-2 as follows

$\operatorname{SEM}_{\overline{F_{\mathrm{s}}}}=\frac{\sigma_{\text {ret }}}{\sqrt{n}}$,

where $\sigma_{\text {ret }}$ is the standard deviation and $n$ is the number of observations per grid cell. In contrast to Eq. (10), this value is a measure of instrumental noise plus natural variability of SIF in the considered time range.

\section{Sensitivity analysis}

The retrieval approach has been tested for a wide range of conditions using simulated radiances in order to assess retrieval precision and accuracy, the effect of the backward elimination algorithm as well as the optimal retrieval window. This section describes the underlying simulations briefly and examines retrieval properties and advantages with respect to a simple linear model without a backward elimination. 


\subsection{Simulated TOA radiances}

As in Joiner et al. (2013), we use simulated sun-normalized TOA radiances from the Matrix Operator MOdel (MOMO) radiative transfer code (Fell and Fischer, 2001) with a spectral sampling of $0.005 \mathrm{~nm}$. We take the widely used spectral library from Chance and Kurucz (2010) to simulate the solar irradiance. The simulations include two viewing zenith angles $\left(0\right.$ and $\left.16^{\circ}\right)$, four solar zenith angles $(15,30,45$ and $70^{\circ}$ ), two atmospheric temperature profiles (middle latitude summer and winter), four surface pressures $(955,980,1005$ and $1030 \mathrm{hPa})$, four water vapor columns $(0.5,1.5,2.5$ and $4.0 \mathrm{~g} \mathrm{~cm}^{-2}$ ), three aerosol layer heights $(500-700,600-800$ and $700-900 \mathrm{hPa}$ ) using a continental aerosol model and five aerosol optical thicknesses at $550 \mathrm{~nm}(0.05,0.12,0.2,0.3$ and 0.4). Apart from the observation and illumination geometry, simulations for 480 different atmospheric states have been carried out in order to test the retrieval. In this case, the training set uses a spectral library of 10 different soil and snow surface reflectance spectra, which means that the training data contain 38400 samples. A set of top-of-canopy (TOC) reflectances and SIF spectra derived with the FluorSAIL radiative transfer model has been utilized to produce the test data set. The surface reflectance is thereby a function of chlorophyll content and leaf area index (LAI), while SIF is a function of chlorophyll content $\left(5,10,20\right.$ and $\left.40 \mu \mathrm{g} \mathrm{cm}^{-2}\right)$, LAI $\left(0.5,1,2,3\right.$ and $\left.4 \mathrm{~m}^{2} \mathrm{~m}^{-2}\right)$ and quantum efficiency (which affects the intensity of the SIF flux; 0.02, 0.05 and 0.08). It follows from these 60 diverse TOC fluorescence spectra and various simulations that the test data are composed out of 230400 samples. We convolve the high spectral resolution TOA spectra $(0.005 \mathrm{~nm})$ to a lower resolution spectrometer grid with a $0.5 \mathrm{~nm}$ full-width at half-maximum and a spectral sampling interval of $0.2 \mathrm{~nm}$ which is similar to GOME-2 and SCIAMACHY. A realistic instrumental noise with respect to the calculated SNR from GOME-2 (in relation to the radiance level at a reference wavelength) provided by EUMETSAT is then added to the spectra using Eq. (7).

\subsection{End-to-end simulation}

Figure 5 depicts the result of the end-to-end simulation using the described retrieval approach with a fitting window ranging from 720-758 nm and providing eight PCs (derived from the synthetic training set). The mean and standard deviation of the 480 simulated atmospheric states as well as the illumination and observation angles were calculated for each of the 60 TOC SIF spectra.

The good correlation between simulated and retrieved SIF in Fig. 5 suggests that the retrieval approach is basically appropriate for the separation of the SIF signal from the TOA radiance. However, to enhance confidence and to prove that several potential systematic effects can be excluded, we depict the retrieved minus simulated SIF in dependence on the

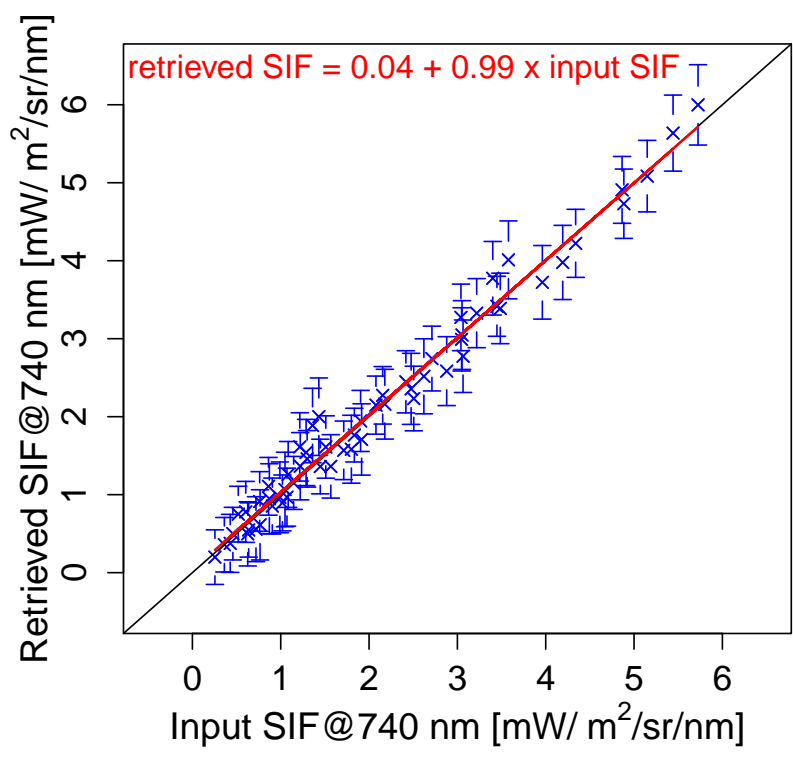

Figure 5. Input vs. retrieved SIF at $740 \mathrm{~nm}$ of the end-to-end simulation using the retrieval window from $720-758 \mathrm{~nm}$ and providing eight PCs. The average of the retrieved SIF for each top-of-canopy (TOC) measurement is shown together with its standard deviation (error bar). A linear fit of all TOC means is shown in red.

simulated solar zenith angle, the water vapor column and aerosol optical thickness at $550 \mathrm{~nm}$ in Fig. 6.

The only visible bias is with respect to the solar zenith angle. Low illumination angles cause a slightly higher variance, which can be expected since the noise level increases with a higher TOA radiance.

Figure 7 illustrates the extent to which the theoretical random error, calculated through Eq. (8), matches the actual precision error. It can be seen that the root-mean-square error (denoted by crosses) is higher than the majority of our theoretical error estimates, but well within the statistical spread. This is due to the fact that the forward model is an approximation; therefore, small systematic errors (as can be seen in Fig. 5) occur, which are not represented in the retrieval error covariance matrix $\mathbf{S}_{\mathrm{e}}$. Furthermore, Fig. 7 reveals that the error (theoretical and actual) increases slightly with the signal level.

In view of the good correspondence between input and retrieved SIF in the end-to-end simulation, it can be stated that the retrieval method is appropriate. One limitation of this sensitivity study consists of the absence of clouds, which inevitably impact the retrieval of SIF. The result of other simulation studies by Frankenberg et al. (2012) and Guanter et al. (2015) suggests that an underestimation of SIF can be expected in the presence of clouds. The reason is a shielding effect, which is not captured by the forward model. Nevertheless, this should be of secondary importance when evaluating the pure retrieval methodology. Furthermore, we will assess 

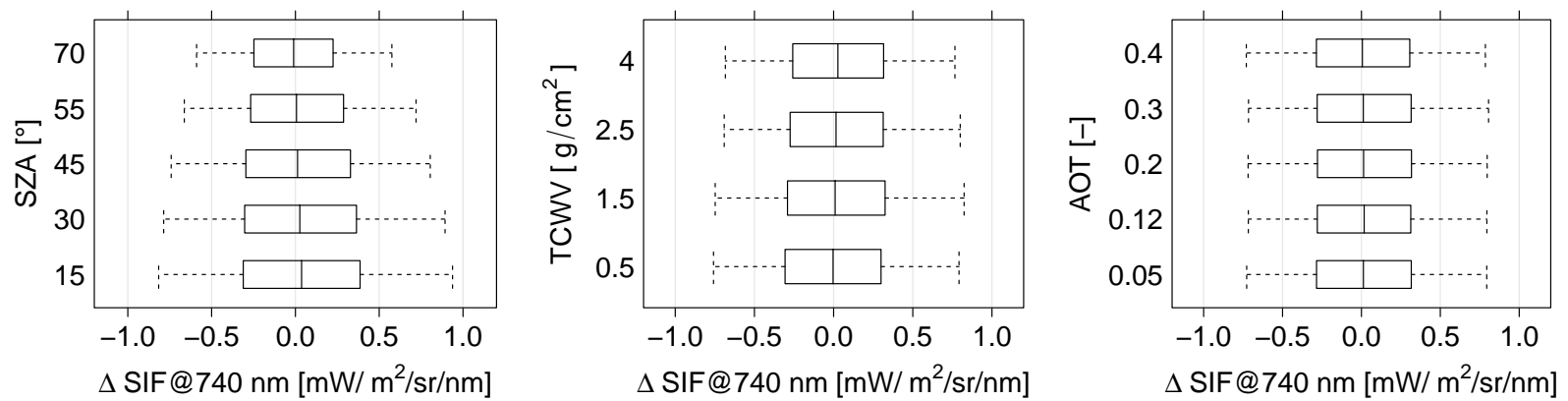

Figure 6. Retrieved minus simulated SIF in dependence on the simulated solar zenith angle (SZA), the water vapor column (TCWV) and aerosol optical thickness at $550 \mathrm{~nm}$ (AOT) for the same retrieval properties as in Fig. 5 (eight provided PCs, 720-758 nm retrieval window). The vertical bar represents the median, the box/error bar covers $50 / 90 \%$ of differences.

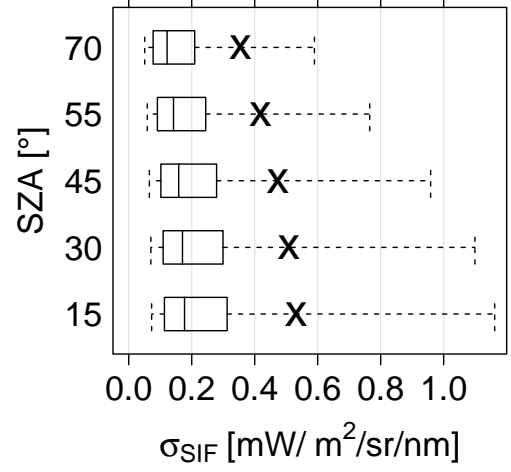

Figure 7. Estimated SIF error in dependence on the simulated solar zenith angle (SZA) for the same retrieval properties as in Fig. 5 (eight provided PCs, 720-758 nm retrieval window). The vertical bar represents the median, the box/error bar covers 50/90\% of the theoretical random errors as calculated from Eq. (8). The crosses denote the estimated root-mean-square errors of the simulation-based retrieval test.

the impact of clouds on the retrieval based on real satellite measurements in Sect. 5.7.

\subsection{Influence of number of PCs used and backward elimination}

We performed the retrieval several times using 5-25 PCs in order to assess the sensitivity to the number of provided PCs. In addition, the backward elimination algorithm was disabled (all $4 \cdot n_{\mathrm{PC}}+1$ coefficients from Eq. 5 are used) to evaluate whether the algorithm is capable of reducing the noise and avoid an overfitting. Results are presented in Fig. 8 in form of various statistical comparisons which are evaluated and described below.

The first plot in Fig. 8 shows the average number of selected atmospheric PCs and coefficients as a function of provided PCs. This plot is insufficient to decide how many atmospheric PCs should be provided to the algorithm, but it reveals that a saturation occurs at about seven selected PCs and
15 coefficients (combination of a third-order polynomial in wavelength with individual PCs), respectively. In the following, it should be taken into account that the linear model fit contains all $4 \cdot n_{\mathrm{PC}}+1$ coefficients, while the backward elimination algorithm selects a maximum number of nine PCs $/ 21$ coefficients with a probability of not being exceeded in $90 \%$ of cases.

The bias which was calculated through the mean difference of retrieved minus input SIF represents the accuracy of the retrieval. It can be seen that the bias drops down to a value close to zero when providing more than seven PCs for both the linear model fit and the backward elimination fit. Using all coefficients leads to a slightly increasing positive bias associated with a larger number of PCs, which is not the case when the backward elimination is applied. Consequently, an unnecessary complex model would potentially result in overestimated SIF values.

A difference between the disabled and enabled backward elimination algorithm can also be seen in the comparison of the mean standard deviation. Here, the resulting standard deviations of the retrieved SIF under differing atmospheric conditions for the 60 TOC SIF spectra were averaged to assess the retrieval precision. It can be noted that the precision of the backward elimination fit remains constant, while the linear model fit loses precision with a larger number of PCs. Also this comparison suggests providing at least seven PCs to the retrieval.

More pronounced differences arise in the comparison between the mean Bayesian information criterion (BIC) values. This fact is expected since the number of coefficients serves as weight for this criterion (as described in Sect. 3.5). For an interpretation of the BIC it has to be noted that the model with the lowest value is to be preferred. As a consequence, the BIC can be used to determine the appropriate number of PCs for the retrieval. It turns out that six to eight PCs should be used for the linear model fit using all coefficients, while at least eight PCs should be provided for the backward elimination fit. This finding concurs with the results from the previous comparisons and supports the applicability of this cri- 

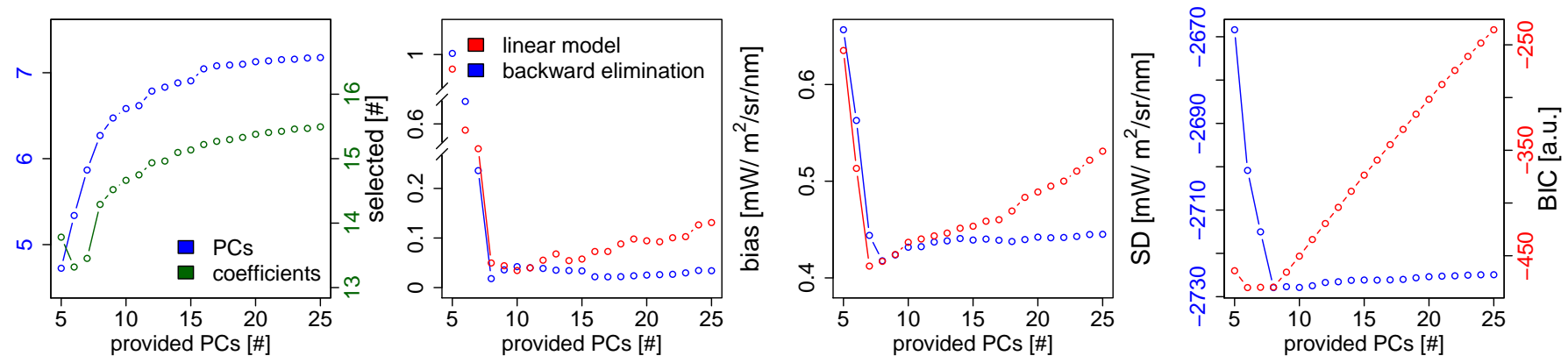

Figure 8. The plot on the left shows the average number of selected PCs (blue) and coefficients (green) as a function of PCs provided to the backward elimination algorithm. In the following, the retrieval results for the linear model fit using all potentials coefficients (red) are compared to the backward elimination fit (blue). Depicted are the bias (mean difference of retrieved minus input SIF), the average standard deviation of retrieved SIF for the 60 TOC SIF spectra (SD) and the mean Bayesian information criterion (BIC).

terion. It should be mentioned that the order of magnitude of BIC values clearly shows that the backward elimination fit should be preferred in any case. A potential overfitting of the measurement can be successfully prevented in this way.

Theoretically, there should be no more variability in data points for large numbers of initial PCs if the model parameter selection is enabled. Although Fig. 8 basically reflects this expectation, there is still a low variability. The reason can be found in the stepwise model selection, which is performed because a test of all possible model parameter combinations would be computationally too expensive (Sect. 3.5).

Even if differences are small, it can be concluded that the accuracy (no significant bias) and precision (decreased average standard deviation) are enhanced when the backward elimination is enabled. Hence the noise is reduced by selecting only appropriate coefficients which is expected to be of particular importance for real satellite measurements. Unfortunately, there is no ground truth against which the retrieval could be adjusted or validated for real satellite measurements. As a consequence, it is not possible to determine the most appropriate number of PCs for real satellite data. Thus, it is advantageous that the backward elimination algorithm ensures stable results, regardless how many PCs are provided (with the restriction that there is a minimum number of required PCs). Furthermore, an overfitting of the measurement is avoided by using the discussed algorithm.

As a conclusion of these findings, we decided to provide initially 10 PCs for the retrieval applied to real GOME-2 and SCIAMACHY data. The backward elimination algorithm selects the required model parameters (a subset of candidate parameters from Eq. 5) based on the BIC for each pixel automatically. In order to prove this assumption and to show that there are no significant correlations of the SIF spectrum to any of the selected model parameters, we supplied 10 PCs (as for the retrieval with satellite data) and calculated the correlation error matrix following Govaerts (2010) for a sample fit (Fig. 9).
Table 1. Comparison of different retrieval windows. Shown is the linear fit (retrieved SIF = intercept + slope $\cdot$ input SIF) for supplying the most appropriate number of PCs (determined as in Fig. 8).

\begin{tabular}{lccc}
\hline Exp. & Fitting window & No. of PCs & linear fit \\
\hline 1 & $735-758$ & 5 & $y=0.09+0.91 \cdot x$ \\
2 & $730-758$ & 6 & $y=0.10+0.89 \cdot x$ \\
3 & $725-758$ & 7 & $y=0.05+0.92 \cdot x$ \\
4 & $720-758$ & 8 & $y=0.04+0.99 \cdot x$ \\
5 & $715-758$ & 10 & $y=0.04+0.97 \cdot x$ \\
6 & $710-758$ & 11 & $y=0.26+0.86 \cdot x$ \\
\hline
\end{tabular}

As can be seen, correlations of selected model parameters with $\boldsymbol{T}_{\uparrow}^{\mathrm{e}} \cdot \boldsymbol{h}_{\mathrm{f}}$ are not perfectly zero but absolute values do not exceed 0.3 . Higher correlations between other model parameters occur, especially for those containing the same PC. However, this is unimportant since it is not intended to interpret the concerned coefficients. These model parameters are solely necessary to obtain an appropriate fit to the measurement. Nevertheless, it should be noted that higher correlations between $\boldsymbol{T}_{\uparrow}^{\mathrm{e}} \cdot \boldsymbol{h}_{\mathrm{f}}$ and other model parameters cannot per se be excluded because the algorithm selects the model parameters for each single measurement independently of correlations. A further test of the correlation of the PCs obtained by SCIAMACHY and the assumed SIF spectral shape $\left(\boldsymbol{h}_{\mathrm{f}}\right)$ suggests that there are only low correlations (mean correlation coefficient is 0.2 ).

\subsection{Selection of the retrieval window}

In order to justify the $720-758 \mathrm{~nm}$ retrieval window, we performed retrievals in additional fitting windows (710-758, $715-758,725-758,730-758,735-758 \mathrm{~nm}$ ). Table 1 provides the linear fit results for supplying the most appropriate number of PCs to the retrieval algorithm in each tested fitting window. This number has been determined with the help of a statistical comparison as it is shown in Fig. 8. 


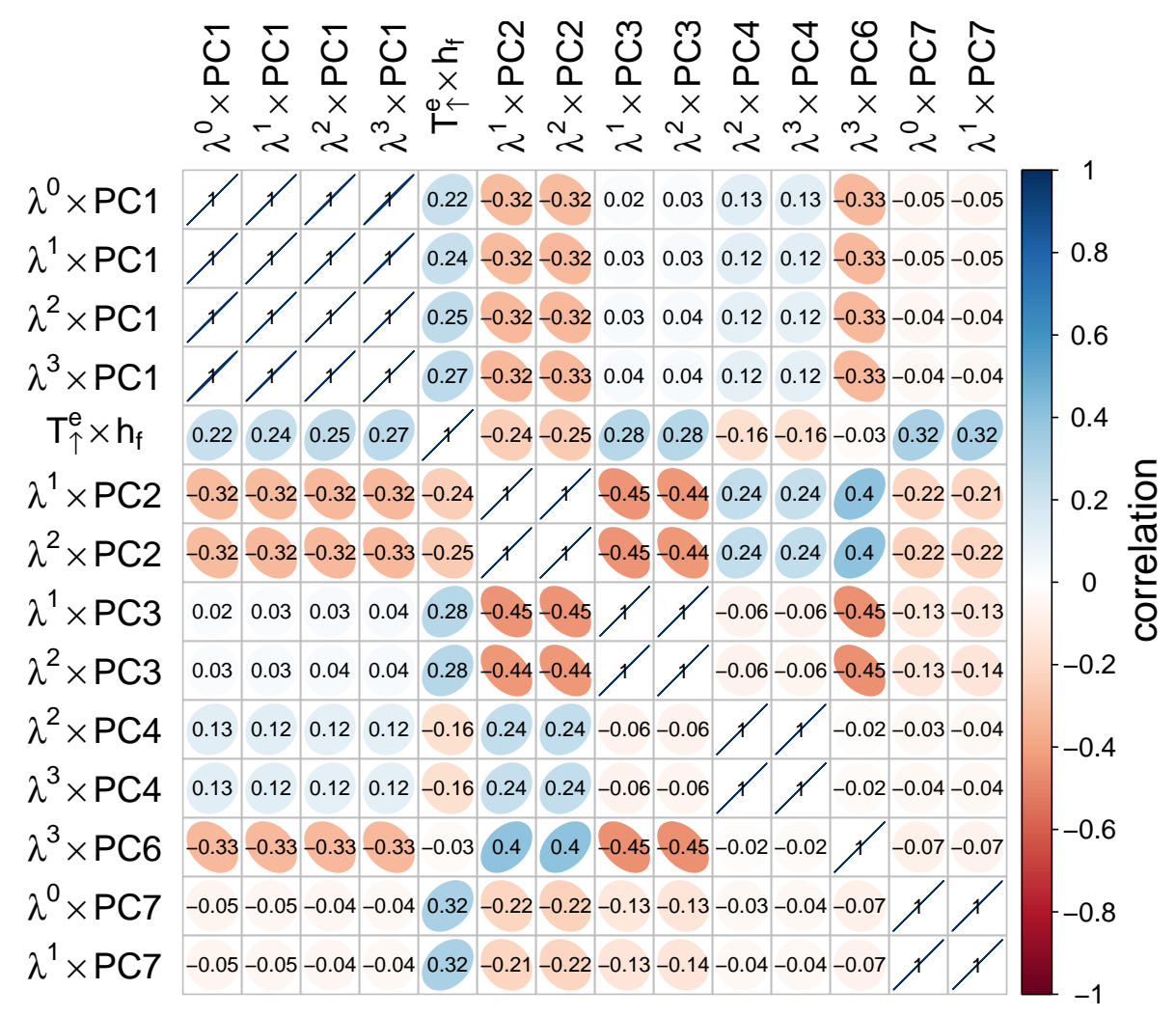

Figure 9. Correlation error matrix of a sample retrieval. A total of $10 \mathrm{PCs}$ were supplied, atmospheric conditions were set to a middle latitude summer temperature profile, $955 \mathrm{hPa}$ surface pressure, $700-500 \mathrm{hPa}$ aerosol layer height, 0.05 aerosol optical thickness, $0.5 \mathrm{~g} \mathrm{~cm}^{-2}$ water vapor column. The retrieved/input SIF at $740 \mathrm{~nm}$ amounts to $1.72 / 1.79 \mathrm{~mW} \mathrm{~m}^{-2} \mathrm{sr}^{-1} \mathrm{~nm}^{-1}$.

We found that both confined and extended retrieval windows lead to a slight bias. Furthermore, the extended retrieval windows require a larger number of PCs. The selected retrieval window from $720-758 \mathrm{~nm}$ is therefore reasonable in terms of retrieval accuracy and computation time. It might be worth noting that the described retrieval approach suggests using significantly less PCs as opposed to Joiner et al. (2014), where the latest algorithm (V25) uses 12 PCs in a retrieval window ranging from $734-758 \mathrm{~nm}$. In the following, further theoretical aspects to select the retrieval window are discussed.

It is known that vegetation has a unique, spectrally smooth reflectance signature in the considered wavelength ranges, which means that there are no distinct absorption lines. Nevertheless, the spectral reflectance of vegetated areas changes rapidly in the red edge region $(680-730 \mathrm{~nm})$, which is due to the spectral variation in chlorophyll absorption. Using the narrow atmospheric window at $722 \mathrm{~nm}$ assures that the apparent reflectance (which is in turn used to estimate $\boldsymbol{T}_{\uparrow}^{\mathrm{e}}$ ) can be modeled with sufficient precision for the part of the retrieval window which is affected by the red edge. Extending the retrieval window to lower wavelengths would lead to errors in the reflectance estimation caused by a lack of further atmospheric windows (the next spectral region with a high atmospheric transmittance is located at wavelengths below $710 \mathrm{~nm}$ ). This error translates into the transmittance estimation, which propagates to errors in SIF. Extending the retrieval window to the $\mathrm{O}_{2}$ A-band at $760 \mathrm{~nm}$ would be possible and has also been shown by Joiner et al. (2013), but a benefit cannot be expected. As already stated by Frankenberg et al. (2011a), the separation from SIF and atmospheric scattering properties is ambiguous when using only $\mathrm{O}_{2}$ absorption lines. Also Joiner et al. (2013) reported that the removal of the $\mathrm{O}_{2} \mathrm{~A}$-band is not accompanied with a significant loss of information content. On the other hand, it is possible to confine the retrieval window, whereby a loss of information content regarding SIF is expected, which leads to a loss of retrieval precision and accuracy as can be seen in Table 1 .

Advantages of the $720-758 \mathrm{~nm}$ retrieval window can be summarized as follows:

1. it covers the second peak of SIF emission at $740 \mathrm{~nm}$;

2. it contains spectral regions with a high atmospheric transmittance (between 721.5-722.5 and 743-758 nm), which is necessary to characterize the apparent reflectance and in turn $\boldsymbol{T}_{\uparrow}^{\mathrm{e}}$. 


\section{Results}

The presented SIF retrieval method has been used to produce a global SIF data set from GOME-2 data covering the 2007-2011 time period. In addition, the SIF retrieval has been implemented for SCIAMACHY data for the August 2002-March 2012 time span. This section describes the application of the algorithm to the satellite data, results from spatiotemporal composites as well as a comparison to the results from Joiner et al. (2014). In addition, we compare the GOME-2/SCIAMACHY SIF results to a SIF data set derived from GOSAT data by Köhler et al. (2015). We also discuss an important limitation, which arises due to the South Atlantic Anomaly (SAA). Furthermore, the impact of clouds on the retrieval will be assessed.

\subsection{Application to GOME-2 and SCIAMACHY data}

In contrast to the synthetic data set, where training and test sets are clearly separated, the real satellite data are first partitioned as described below.

The selection of the training set is relevant to obtain meaningful results because these data are used to model the planetary reflectance of the desired measurements over land (test set). It is therefore essential to capture as many atmospheric states and non-fluorescent surfaces as possible within the training set to ensure its representativeness. Random samples of measurements over areas where no SIF signal is expected (e.g., deserts, ice and sea regardless of the degree of cloudiness) are used for this purpose. The selection of such measurements is based on the determination of the land cover using the International Geosphere and Biosphere Programme (IGBP) classification (Friedl et al., 2002) derived from MODIS data. Care is taken to ensure that only homogeneous, non-vegetated land cover classes or measurements over sea and ice serve as a basis for the training set. Furthermore, it has to be noted that the training set is sampled on a daily basis for GOME-2 and a 3-day basis for SCIAMACHY data. The different period of time to sample the training data is due to the reduced number of soundings from SCIAMACHY. Based on the sampled training data, the atmospheric PCs are calculated as explained earlier. Instrumental artifacts and degradation are expected to be captured by this method and do not need to be considered.

In general, the test set is composed of all available land pixels, but cloud-contaminated measurements might make it problematic to retrieve SIF since it can be expected that the SIF signal is partly shielded in the presence of clouds, which potentially biases the retrieval. For this reason, the range of cloud fractions is limited to 0.5 , which saves also computation time, whereas the restriction is explicitly not applied to the training set. We use the effective cloud fraction from the Fast Retrieval Scheme for Clouds from the $\mathrm{O}_{2}$ A-band (FRESCO, Wang et al., 2008). In the case of GOME-2, the provided cloud fraction is already attached to the level $1 \mathrm{~B}$ satellite data. The FRESCO cloud fraction data for SCIAMACHY were available separately and had to be collocated.

The FRESCO cloud fraction is not available for the presence of snow and ice, which is of particular relevance in the winter time at higher latitudes. In order to obtain a complete time series of SIF in affected regions, we evaluate also measurements with an unknown cloud fraction in the presence of snow. Hence, measurements over snow are determined using the ERA-Interim re-analysis data (Dee et al. , 2011) on a $0.75^{\circ}$ grid. The general cloud fraction threshold of 0.5 will be further discussed in Sect. 5.7.

Following the results of our sensitivity analysis, at least eight PCs should be provided for the SIF retrieval in the 720 $758 \mathrm{~nm}$ spectral window. Furthermore, it has been evaluated that the number of provided PCs is not affecting retrieval results as long as we provide more PCs than actually necessary. In contrast to the simulations, some PCs may also account for instrumental effects when applying the algorithm to real data. For this reason, we provided initially 10 PCs for the retrieval using real satellite data. It has emerged that the algorithm selects on average 6 PCs and decides in about $3 \%$ of cases that 10 PCs are actually needed when GOME-2 data are used. This finding corresponds to our sensitivity analysis, where on average seven PCs are selected. However, this changes when the retrieval is applied to SCIAMACHY data. In this case, the algorithm decides in about $40 \%$ of cases that 10 PCs are needed. Therefore, we increased the number of provided PCs to 20, whereas on average 14 PCs are selected. The probability that all 20 PCs are selected is below $1 \%$. It is unclear why SCIAMACHY requires twice the number of PCs as GOME-2.

As a consequence of these findings, we provided $10 \mathrm{PCs}$ for the retrieval for GOME-2 and 20 PCs when SCIAMACHY data are used. The processed data can be retrieved from ftp://ftp.gfz-potsdam.de/home/mefe/GlobFluo/.

\subsection{Quality control}

Since it cannot be excluded that the retrieval fails for single measurements, the retrieval results have to be checked. This is done by using the residual sum of squares (RSS) from each retrieval. The resulting coefficients are used to generate a synthetic measurement which is compared with the original measurement. The RSS value is then the discrepancy between the data and the model. One major issue, which causes high residuals, is the South Atlantic Anomaly (SAA), discussed below in Sect. 5.5. In general, it appears that the RSS value is around $0.5\left(\mathrm{~mW} \mathrm{~m}^{-2} \mathrm{sr}^{-1} \mathrm{~nm}^{-1}\right)^{2}$. Single retrievals are removed if the RSS is above $2\left(\mathrm{~mW} \mathrm{~m}^{-2} \mathrm{sr}^{-1} \mathrm{~nm}^{-1}\right)^{2}$ for both GOME-2 and SCIAMACHY. It turned out, that monthly composites from GOME-2 SIF retrieval results contain striping effects from single swaths in individual cases. This issue might be caused by special orbits (e.g., narrow swath) and is solved by removing distinct swaths with a high average of RSS values (above $\left.1\left(\mathrm{~mW} \mathrm{~m}^{-2} \mathrm{sr}^{-1} \mathrm{~nm}^{-1}\right)^{2}\right)$. This striping 

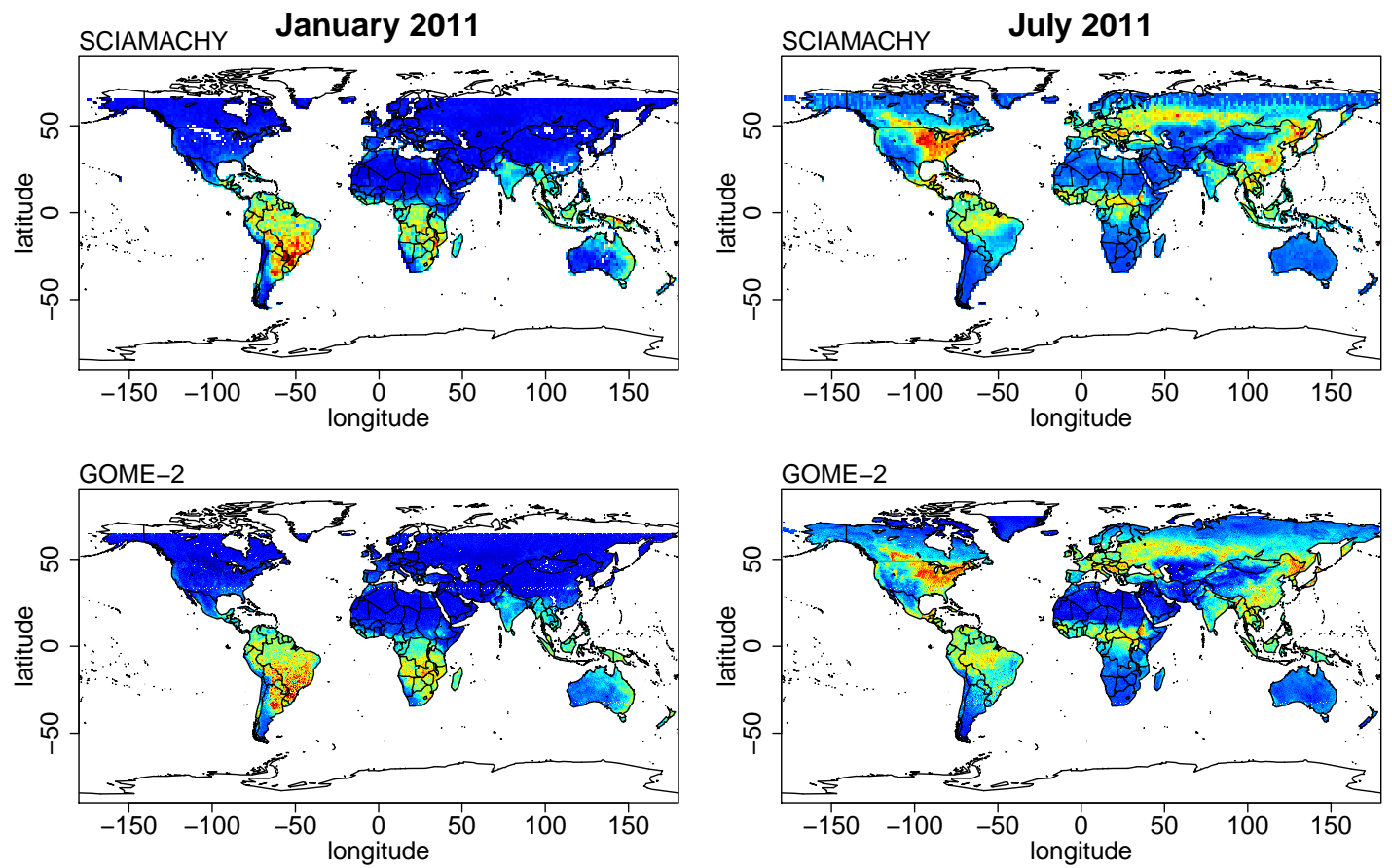

4

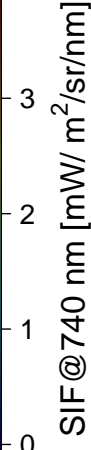
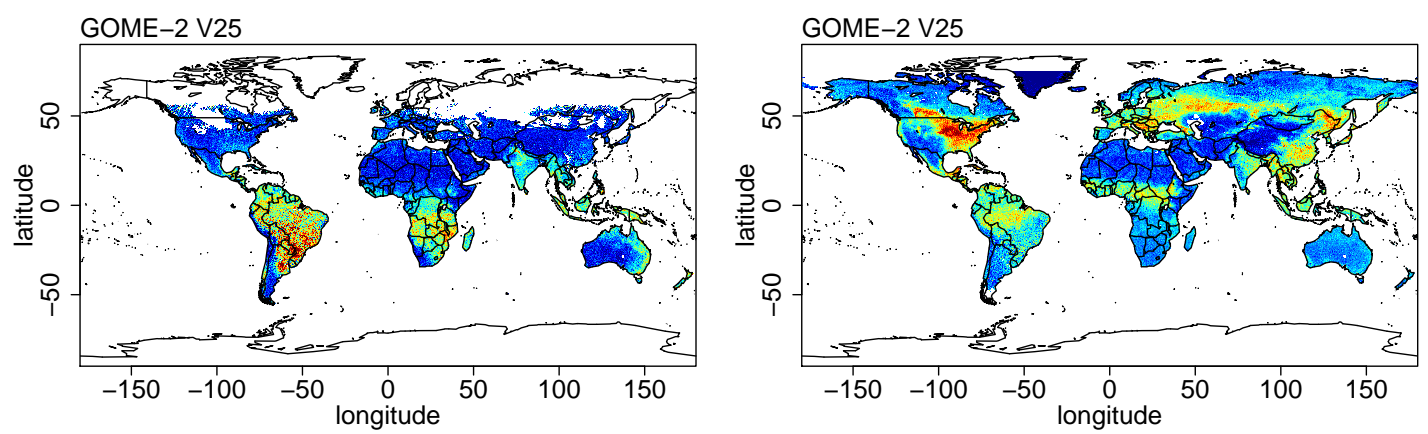

Figure 10. Monthly composites of SIF at $740 \mathrm{~nm}$ for January (left column) and July (right column) 2011. The upper row depicts SIF results using SCIAMACHY data and the rows below show SIF composites derived from GOME-2 data using our algorithm (middle row) and SIF results provided by Joiner et al. (2014) (bottom row). The SCIAMACHY composites and results from Joiner et al. (2014) are scaled by the relationships in Table 2 to ensure a good visual comparison.

effect was not observed for SIF results obtained from SCIAMACHY. Further filtering besides the residual check is not applied to our data set.

\subsection{Spatiotemporal composites}

In principle, it is possible to achieve a global coverage of SIF measurements within 1.5 days for GOME- 2 and 6 days for SCIAMACHY, but the presence of clouds prevents such a high temporal resolution. Although it is important to consider different time scales, it is common to produce monthly means. Two monthly composites of SIF in January and July 2011 derived from SCIAMACHY and GOME-2 data are shown together with V25 GOME-2 SIF results provided by Joiner et al. (2014) in Fig. 10.
Overall all three results compare very well concerning spatial patterns, although the SIF composite derived with SCIAMACHY is provided in a spatial resolution of $1.5^{\circ} \times$ $1.5^{\circ}$, whereas SIF retrievals from GOME- 2 are rastered in $0.5^{\circ} \times 0.5^{\circ}$ grid boxes. The lower spatial resolution for SCIAMACHY is due to the fact that the original pixels are coadded in certain wavelength regions in order to meet downlink limitations. However, it must be stated that absolute SIF values obtained from SCIAMACHY are slightly lower than from GOME-2, although such a difference is not expected since the overpass time differs only half an hour.

One reason might be a higher cloud contamination of the bigger footprints from SCIAMACHY. As already stated in Sect. 4.2, simulation studies by Frankenberg et al. (2012) and Guanter et al. (2015) have shown that an underestimation of SIF caused by a extinction through clouds can be expected. 

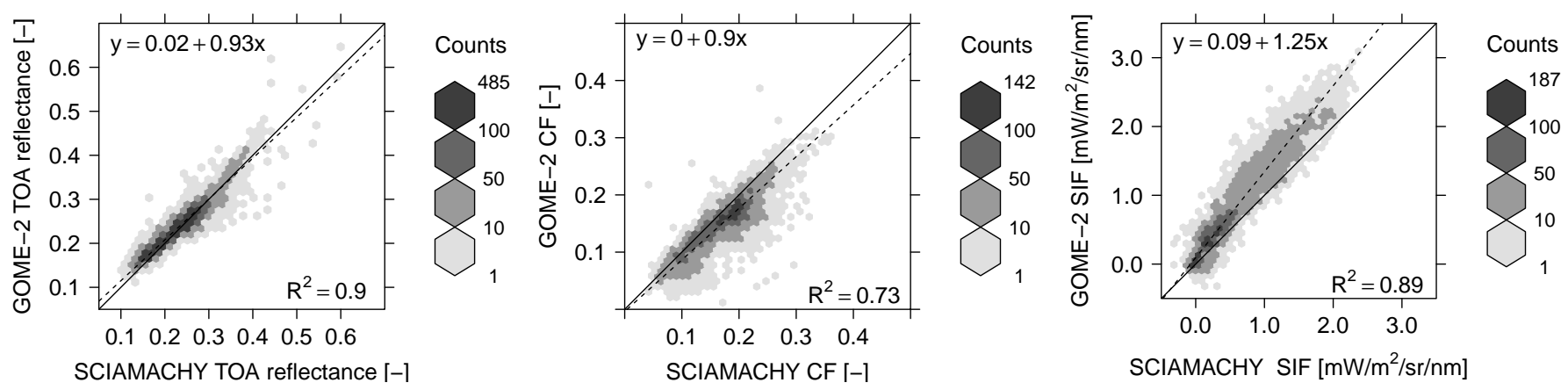

Figure 11. GOME-2 versus SCIAMACHY data of TOA reflectance at $720 \mathrm{~nm}$, FRESCO (Wang et al., 2008) cloud fractions (CF) and SIF. Averages from February 2007 to December 2011 (rastered on $1.5^{\circ} \times 1.5^{\circ}$ grid) with a cloud fraction lower than 0.5 have been used. The linear fits are depicted as dotted lines.

Table 2. Relationship between SIF values derived from GOME-2 and SCIAMACHY on a monthly basis to scale SCIAMACHY and V25 GOME-2 SIF values in Fig. 10. Shown is the linear fit (GOME$2 \mathrm{SIF}=$ intercept + slope $\cdot$ SCIAMACHY/V25 SIF) similar to those in Figs. 11 and 14.

\begin{tabular}{lcc}
\hline ... vs. GOME-2 & January 2011 & July 2011 \\
\hline SCIAMACHY & $y=0.03+1.42 \cdot x$ & $y=0.35+0.95 \cdot x$ \\
V25 GOME-2 & $y=-0.09+2.18 \cdot x$ & $y=0.29+1.64 \cdot x$ \\
\hline
\end{tabular}

Another possible reason could be a relative radiometric offset between the two satellite sensors. Therefore, we assess the TOA reflectance at $720 \mathrm{~nm}$ (lower limit of the fitting window), the FRESCO cloud fraction and the retrieved SIF for the overlapping data sets in time from GOME-2 and SCIAMACHY in Fig. 11.

As can be seen from the TOA reflectance comparison, there is most likely no offset. When considering the cloud fractions, the overall linear fit is comparable to that of the TOA reflectance but points scatter more widely $\left(\mathrm{R}^{2}=0.73\right)$ with a visible tendency to higher cloud fractions of the SCIAMACHY data. In contrast, the scattering of retrieved SIF values is not widespread $\left(\mathrm{R}^{2}=0.89\right)$ but GOME-2 SIF values are higher by a factor of 1.25 . In view of these results, it is likely that lower SCIAMACHY SIF values are at least partly associated with a higher cloud contamination. Nevertheless, it needs to be mentioned that the relationship between SIF values from GOME-2 and SCIAMACHY is seasonally dependent. In order to ensure a good visual comparison, derived SIF values from SCIAMACHY data are therefore scaled in Fig. 10 by the relationship, which is obtained from monthly means (see Table 2).

The January 2011 SIF composites in Fig. 10 comprise a high SIF average in South America which must be treated with caution, because this region is particularly affected by the South Atlantic Anomaly. This limitation will be discussed in Sect. 5.5 but it should already be considered at this point to avoid a misinterpretation. Concurrently, SIF values in the Northern Hemisphere are close to 0 , which is owing to the inactivity of vegetation during this month. The appearance of the map changes fundamentally for July. It is interesting to note the high SIF average in the US Corn Belt region with respect to other regions at the same latitude, which is produced by large crop- and grassland areas. This region with pronounced SIF averages was examined in detail by Guanter et al. (2014) with the finding that SIF retrievals provide a basis for a reliable estimation of gross primary production (GPP) in cropland and grassland ecosystems. Furthermore, it has been stated that current carbon cycle models on average underestimate the GPP in such regions.

Figure 12 depicts a time series of monthly averages over a sample cropland area between $100-80^{\circ} \mathrm{W}, 35-50^{\circ} \mathrm{N}$ (shown in Fig. 16) in order to investigate the temporal consistency of our SIF retrieval algorithm. Therefore, the retrieval output (without averaging the results in grid boxes) in that area has been collocated with the IGBP classification (Friedl et al., 2002). Those retrievals which were classified as cropland with cloud fractions lower than 0.5 or unknown cloud fractions in the presence of snow, serve as the basis for the monthly SIF averages in Fig. 12. Both time series show an aligned annual cycle with high SIF values during summertime. Beside the difference in absolute values (no scaling has been employed) it is noticeable that the interannual variability for the two time series may be slightly inconsistent, but the difference may also be due to noise or the different sampling. Considering that SIF values are close to zero during inactive periods, the standard deviation in wintertime may be used to estimate the precision for the SIF retrieval (specific for the considered area and monthly averages in Fig. 12), which is of the order of $0.2-0.4 \mathrm{~mW} \mathrm{~m}^{-2} \mathrm{sr}^{-1} \mathrm{~nm}^{-1}$. It seems reasonable that the GOME-2 SIF data exhibit a generally higher variability because of the fact that each SCIAMACHY pixel is similar to four averaged GOME-2 pixels.

In order to provide an typical estimate of the uncertainty of monthly SIF composites due to instrumental noise, Fig. 13 


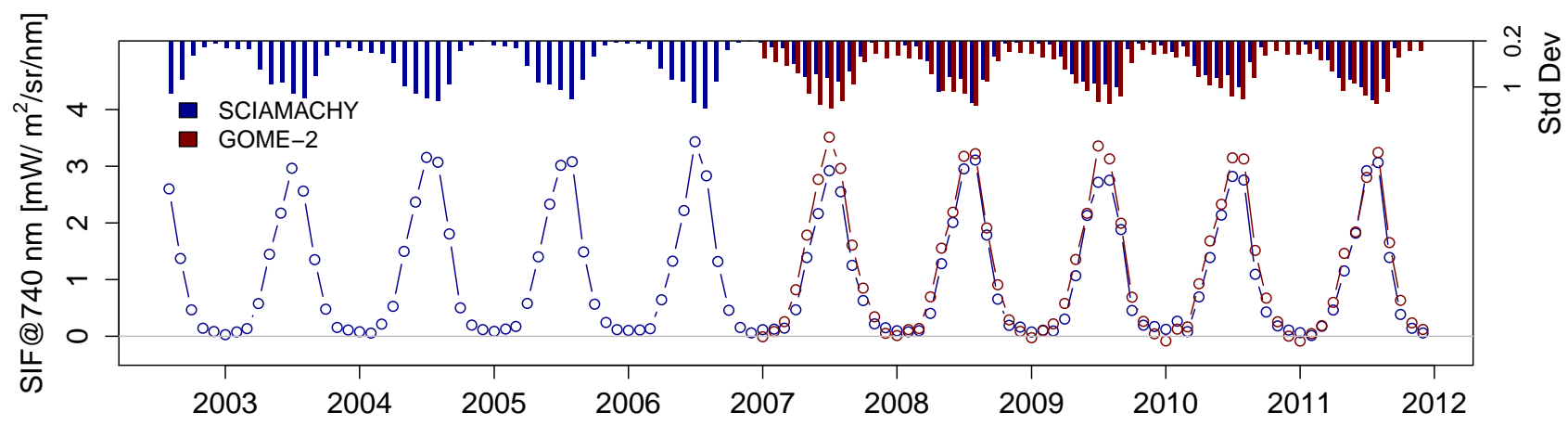

Figure 12. Comparison of monthly SIF averages derived from SCIAMACHY (blue) and GOME-2 (red) for croplands between $100-80^{\circ}$ W, $35-50^{\circ} \mathrm{N}$ (shown in Fig. 16). The standard deviation per time step is depicted as a bar plot.

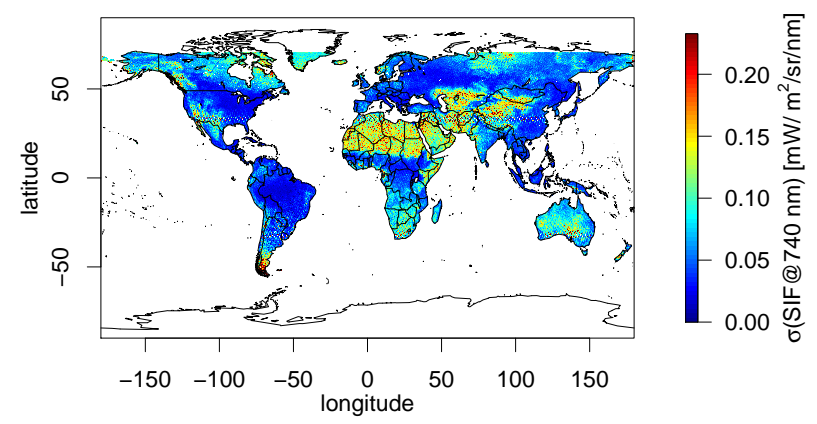

Figure 13. Standard error of the weighted average (using Eq. (10), measure of instrumental noise only) of GOME-2 SIF for July 2011.

shows the standard error of the weighted average (Eq. 10) derived with GOME-2 for July 2011.

Highest uncertainties occur over bright areas associated with a higher photon noise, e.g., deserts and regions with snow/ice. The resulting pattern can therefore be interpreted as an error increasing with TOA radiance.

\subsection{Comparison with existing retrieval results}

Since we present a similar SIF retrieval method to that proposed by Joiner et al. (2013), it is reasonable to compare both results. It should be noted that there are two released versions of GOME-2 SIF (V14 \& V25), whereas this comparison focusses on the latest version (V25) described in Joiner et al. (2014). Main changes from V14 to V25 lie in a confined retrieval window (V14: 715-758 nm, V25: 734-758 nm) and subsequently in a reduced number of PCs used (V14: 25 PCs, V25: 12 PCs). Furthermore, the spectra are normalized with respect to earth spectra instead of the GOME-2 solar spectra in V25. It should be considered that the change in retrieval window has lead to a significant decrease in absolute SIF values.

Similar to Fig. 11, a scatter plot between the V25 data set and SIF values derived with the presented algorithm is de-

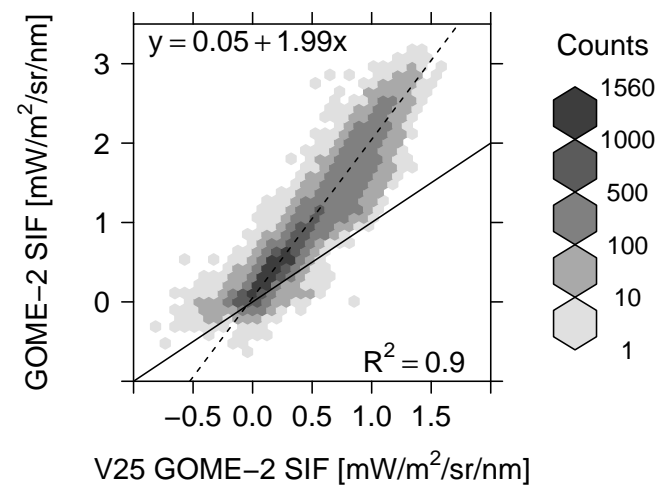

Figure 14. SIF retrieval results from the presented algorithm versus V25 results provided by Joiner et al. (2014). SIF averages from February 2007 to December 2011 (rastered on a $0.5^{\circ} \times 0.5^{\circ}$ grid) with cloud fractions lower than 0.5 have been used. The one-to-one line (solid line) is depicted as well as a linear fit (dotted line).

picted in Fig. 14 for the overlapping period in time (February 2007 to December 2011).

It is immediately noticeable that the absolute SIF values obtained from the presented retrieval are about 2 times higher.

This is inconsistent with our simulation-based retrieval test with a similar fitting window to that of the V25 algorithm from Joiner et al. (2014), which only leads to a decrease of about $10 \%$ in absolute values (see Table 1, Exp. 1). In view of this discrepancy, it must be stated that there are still large uncertainties in absolute SIF values, while spatiotemporal patterns compare well. At the same time, it should be noted that a temporal consistency might be more relevant for potential users of SIF data sets at the moment, since the absolute value is not applied in current research. Although such a large difference is basically not expected, the data sets are highly correlated and there is a clear linear relationship. This relationship also exhibits seasonal variations as shown in Table 2, which has been used to scale the monthly composites in Fig. 10 in order to ensure a good visual comparison. 
At this point, we are not able to judge which absolute values are closer to reality, since there is a lack of ground truth and validation. The only possibility to assess the validity of results from the data-driven approaches, besides the sensitivity analyses, is at present a comparison to physically based SIF retrieval results from GOSAT data. GOSAT and GOME2/SCIAMACHY SIF values are expected to be different, which is due to different overpass times, evaluated wavelengths (GOSAT SIF is evaluated between $755-759 \mathrm{~nm}$ ), illumination and especially observation geometries. Nevertheless, it can be presumed that there is a good correlation between those data sets.

In Fig. 15 we compare long-term SIF averages for the June 2009-August 2011 time period from GOME2/SCIAMACHY SIF data to GOSAT SIF retrieval results obtained by Köhler et al. (2015).

The averaging interval has been selected according to the available overlapping periods for all four data sets. The underlying retrieval results are rastered on a $2^{\circ} \times 2^{\circ}$ grid, which is due to the poor spatial sampling of the GOSAT measurements. Furthermore, GOME-2/SCIAMACHY measurements with a cloud fraction lower than 0.5 serve as a basis for the long-term average while the cloud filter for GOSAT soundings consists of an empirical radiance threshold as reported in Köhler et al. (2015). As can be seen in Fig. 15, there is an enhanced correlation to the GOSAT SIF data set for the presented retrieval algorithm. However, a small offset with respect to the GOSAT SIF data set can be observed in all comparisons. Our GOME-2 SIF data has the largest offset, which is probably introduced by a north-south bias in the training set (discussed in Sect. 5.6).

In view of these results, it can be assumed that the presented retrieval approach is not less valid than that of Joiner et al. (2013). In general, spatiotemporal patterns compare very well as can be seen in Fig. 10; nevertheless, it remains unclear which absolute values are more accurate.

\subsection{South Atlantic Anomaly}

Another point to be considered is that the error estimation might be too optimistic for large parts of the South American continent. The reason is the South Atlantic Anomaly (SAA), which is a region of reduced strength in the Earth's magnetic field. Hence, orbiting satellites are exposed to an increased flux of energetic particles, which leads to increased noise in the measurements. An impact of the SAA on the SIF retrieval using GOME-2 data has also been described in the study of Joiner et al. (2013). Here, we depict the standard error of the mean (SEM, Eq. 11) of monthly SIF composites for January and July 2011 from our SIF retrieval using GOME-2 and SCIAMACHY data in Fig. 16 to illustrate the impact of the SAA. This comparison provides also an estimate of the uncertainty, whereas instrumental noise and natural variability are covered. The underlying SCIAMACHY SIF values to produce Fig. 16 are also scaled by the linear relationship in
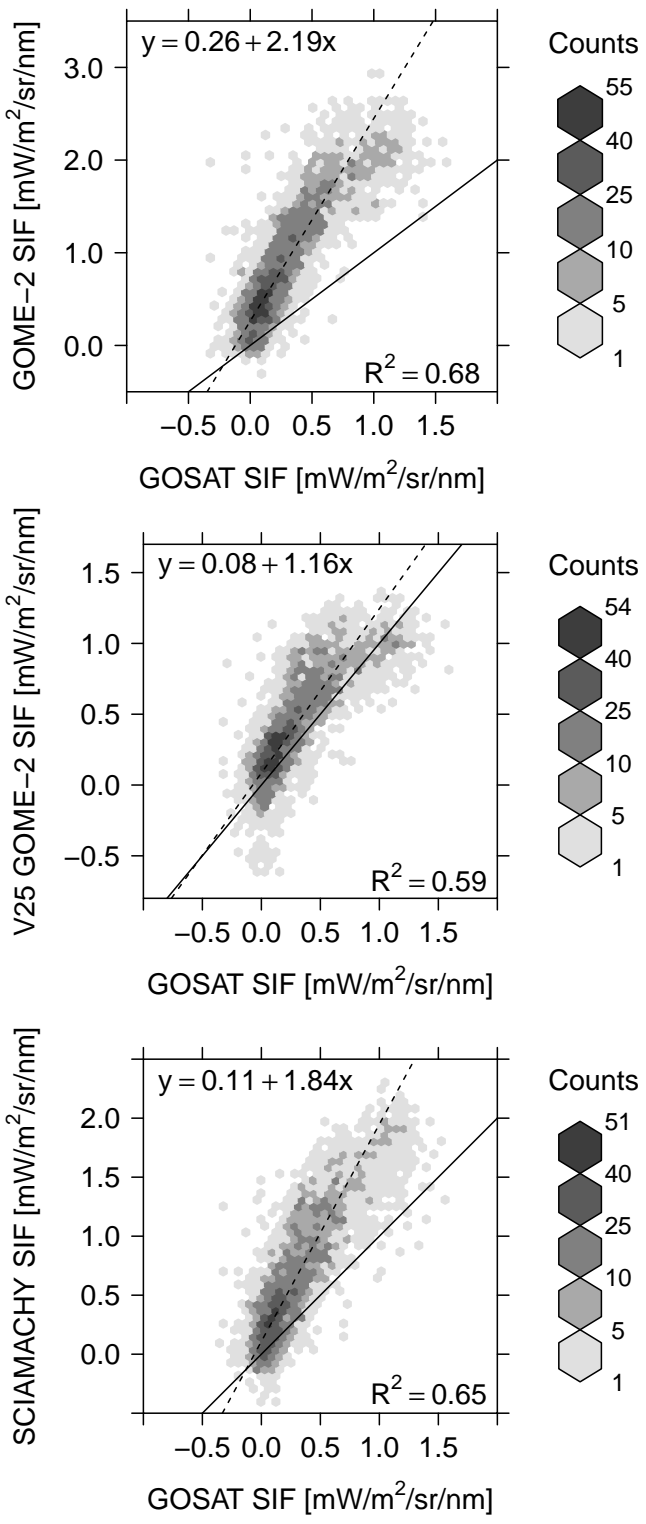

Figure 15. SIF retrieval results from GOSAT (evaluated at $755 \mathrm{~nm}$, Köhler et al., 2015) versus SIF retrieval results from the presented algorithm and V25 results provided by Joiner et al. (2014). SIF averages from June 2009 to August 2011 (rastered on a $2^{\circ} \times 2^{\circ}$ grid) have been used. Each evaluated grid box contains at least 26 retrievals using GOSAT data, included GOME-2/SCIAMACHY SIF retrievals own a cloud fraction lower than 0.5 . The one-to-one line (solid line) is depicted as well as a linear fit (dotted line).

Table 2 and both composites are computed in a spatial resolution of $1.5^{\circ} \times 1.5^{\circ}$ in order ensure a comparison.

The center of the SAA is in close proximity to the coast of Brazil at about $40^{\circ} \mathrm{W}$ and $30^{\circ} \mathrm{S}$, which results in extraordinary high SEM values for the GOME-2 SIF data set in nearby regions. Overall, higher SEM values occur where a significant amount of SIF can be observed (see Fig. 10). It can also be seen that the SEM is generally lower for the GOME-2 

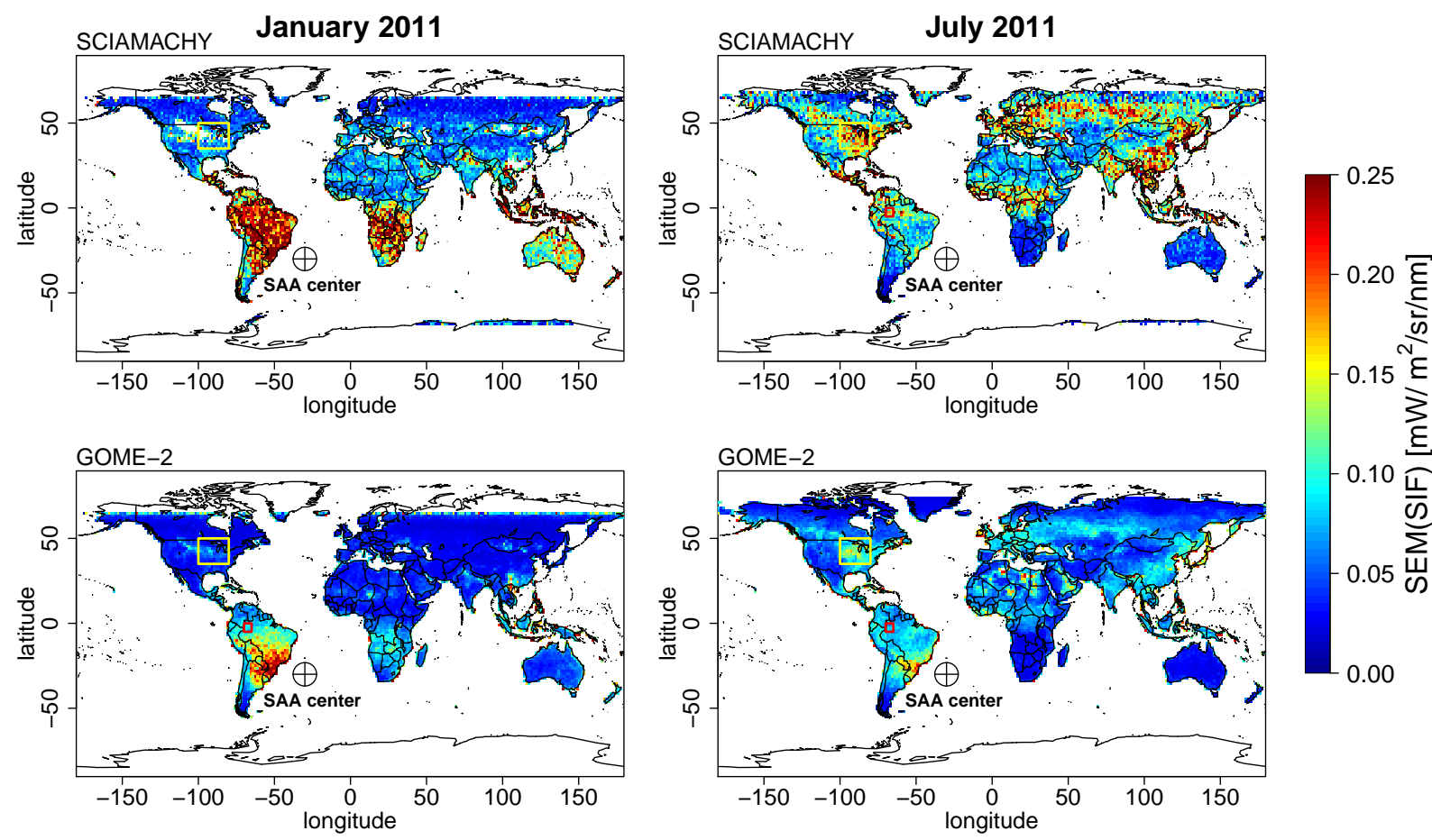

Figure 16. Monthly composites of the standard error of the mean (SEM, Eq. 11) of SIF for January (left column) and July (right column) 2011 derived from SCIAMACHY (top) and GOME-2 data (bottom) in a spatial resolution of $1.5^{\circ} \times 1.5^{\circ}$. The underlying SCIAMACHY SIF values are again scaled by the relationship in Table 2 in order to ensure a good visual comparison. The center of the SAA at $40^{\circ} \mathrm{W}$ and $30^{\circ} \mathrm{S}$, the analyzed region for Fig. 12 (yellow) and the analyzed region for Fig. 18 (red) are depicted in each map.

SIF composites (except for the SAA affected regions). It is remarkable that the SAA seems to have a much lower impact on measurements performed by SCIAMACHY in particular for July 2011, although the difference in orbit height is only about $20 \mathrm{~km}$. In view of Fig. 16 it is even questionable whether there is an impact of the SAA on SCIAMACHY data at all.

In contrast to the SCIAMACHY data set, the impact of the SAA on GOME-2 data translates also to the residual sum of squares (RSS) of the SIF retrieval (not shown). High RSS values occur in particular in the region of large SEM values on the South American continent. This allows the conclusion that the noise and thus the measurement error is much higher than expected from our error propagation depicted in Fig. 13. Although all single retrievals with an RSS bigger than $2\left(\mathrm{~mW} \mathrm{~m}^{-2} \mathrm{sr}^{-1} \mathrm{~nm}^{-1}\right)^{2}$ are filtered, care should be taken when using SIF retrieval results from affected areas, especially for GOME-2 SIF retrievals.

\subsection{North-south bias in training set}

Consistency checks and plausibility controls of the derived SIF values have lead to another source of error. We retrieved SIF values from the training set (sea, desert and ice) with the expectation that all SIF values are close to zero. It turned out that there is a slight time- and latitude-

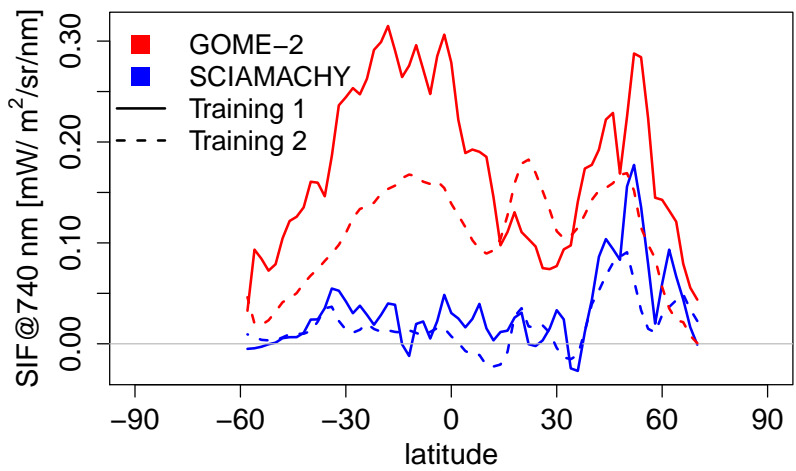

Figure 17. Mean SIF of two different training sets derived with data from GOME-2 and SCIAMACHY averaged over latitudes for July 2011. The first training set (Training 1, solid lines) corresponds to a daily sampling of the data while the second training set (Training 2, dotted lines) is sampled on a 3-day basis.

dependent offset in retrieved SIF values which amounts to up to $0.3 \mathrm{~mW} \mathrm{~m}^{-2} \mathrm{sr}^{-1} \mathrm{~nm}^{-1}$ for GOME-2 SIF results. Two different ways to sample the training data have been tested for July 2011 in order to investigate if this bias is related to the sampling method or if there is an instrumental issue. The first training set has been sampled on a daily basis as explained in Sect. 5.1 for both satellite instruments. In contrast, the second training set has been sampled on a 3-day basis, whereas the 


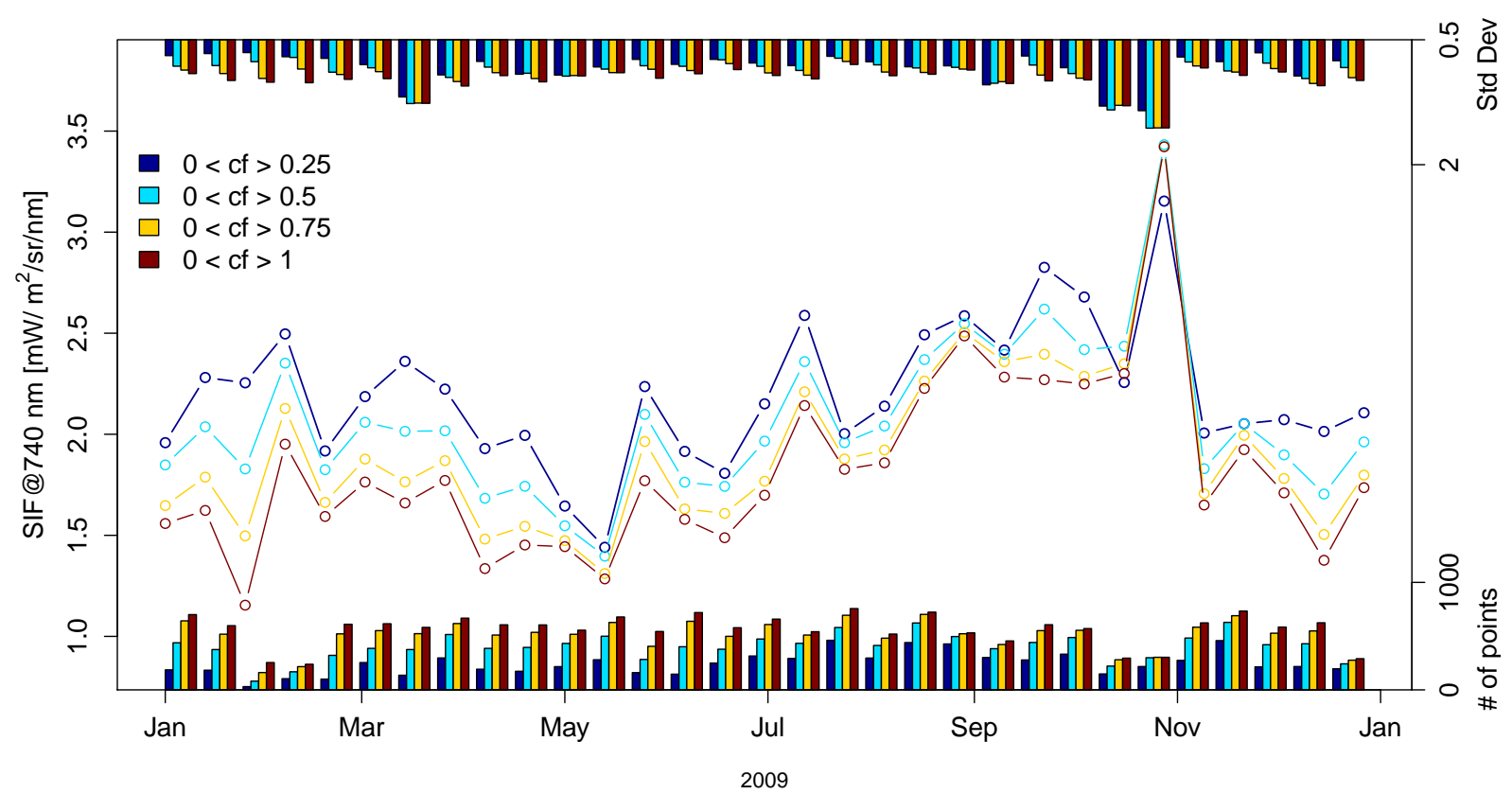

Figure 18. Time series of SIF retrievals from GOME-2 data over a box in the Amazon Basin $\left(70-65^{\circ}\right.$ W, $5-0^{\circ} \mathrm{S}$ (shown in Fig. 16), covered with evergreen broadleaf forest) for different cloud fraction thresholds. The time series corresponds to 12 day means in 2009 . The standard deviation (top) and the number of included retrievals (bottom) per time step are depicted as bar plots.

SAA affected region has been excluded (longitudes between $90^{\circ} \mathrm{W}$ and $15^{\circ} \mathrm{E}$ and latitudes between $10^{\circ} \mathrm{N}$ and $90^{\circ} \mathrm{S}$ ) and spectra have been selected with respect to their latitudinal representativeness (the number of sampled spectra per latitude corresponds to the median number of spectra per latitude). Figure 17 depicts the monthly composite of SIF of the two different training sets averaged over latitudes derived from GOME-2 and SCIAMACHY data for July 2011.

As can be seen, there is almost no difference between the different sampling methods of the SCIAMACHY training data. Nevertheless, a slight offset of about $0.1 \mathrm{~mW} \mathrm{~m}^{-2} \mathrm{sr}^{-1} \mathrm{~nm}^{-1}$ is introduced in latitudes above $40^{\circ} \mathrm{N}$. The offset in retrieved SIF values from the GOME-2 training set is decreased when the second sampling method is applied, even though the latitudinal dependency is conserved and the offset is more pronounced than in the two SCIAMACHY training sets. A slight zero level offset is also observable in the data provided by Joiner et al. (2014), which supports the thesis that this bias is related to an instrumental issue. One reason might be a temperature-dependent dark current change. This issue should be considered in further investigations.

\subsection{Impact of clouds on the retrieval}

In contrast to the usually applied pre-filtering of cloud contaminated measurements (discussed in Sect. 5.1), we run the retrieval using GOME-2 data in 2009 without restricted cloud fractions in order to examine the impact of clouds.
Tropical rainforest areas are frequently covered by clouds and therefore, it is expected that clouds may affect the retrieval of SIF in particular in such regions. Therefore, we produced a time series over a box in the Amazon Basin (70-65 $5^{\circ} \mathrm{W}, 5-0^{\circ} \mathrm{S}$ (shown in Fig. 16), covered with evergreen broadleaf forest) with different cloud fraction thresholds, which is shown in Fig. 18. Care was taken when selecting the area to ensure that the impact of the SAA is as low as possible and the IGBP land cover (Friedl et al., 2002) (evergreen broadleaf forest) is mostly homogenous.

Overall it can be seen that SIF values are decreasing with an increasing cloud fraction threshold, whereby the temporal pattern remains almost unaffected. Using only retrievals with a low cloud fraction $(<0.25)$ implies a significant loss of measurements while the standard deviation (or fluctuation) is only slightly smaller and even equal for some time steps. SIF values successively decrease by relaxing the threshold, which is consistent with the expectation that the SIF signal is partly shielded by clouds (Frankenberg et al., 2012). An exception occurs in one time step where the reported standard deviation is significantly higher than in the other time steps. Simultaneously, the number of included retrievals is low and differences in cloud fraction values from FRESCO are only marginal. For these reasons, the time step at the end of October 2009 is not meaningful to evaluate the impact of clouds on the retrieval. Applying a cloud fraction threshold of 0.5 results in differences about $0.1 \mathrm{~mW} \mathrm{~m}^{-2} \mathrm{sr}^{-1} \mathrm{~nm}^{-1}$ in comparison to the SIF averages of the lowest evaluated cloud fraction. The highest increase of measurements with 
respect to a cloud fraction threshold of 0.25 can be achieved by using measurements with cloud fractions up to 0.5 . A further increase of the cloud fraction has the consequence that more measurements can be used but the amount of SIF averages is distinctly decreasing. It must be noted that results remain consistent for different spatiotemporal scales and the presented region has been chosen as a representative example. On this basis, a cloud fraction threshold of 0.5 is a reasonable compromise between the loss of measurements and changes in the SIF average. As a consequence, we provide the global SIF data set for measurements with cloud fractions lower than 0.5 including also measurements with unknown cloud fractions in the presence of snow. Nevertheless, in view of these results it can be concluded that the presented SIF retrieval method is robust against moderate cloud contamination.

\section{Conclusions}

A new statistically based approach to retrieve SIF from GOME-2 and SCIAMACHY data has been introduced. Building upon previous works from Guanter et al. (2013) and Joiner et al. (2013), our approach solves the important issue of the arbitrary selection of the number of free model parameters.

The basic assumption to retrieve SIF from space is that the contribution of SIF can adequately be separated from low and high frequency components due to surface and atmospheric properties. In our forward model, the low and high frequency components are represented by a combination of a third-order polynomial in wavelength with atmospheric PCs. A backward elimination algorithm selects the required model parameters automatically with respect to the goodness of fit balanced by model complexity. Our sensitivity analysis reveals that the precision is enhanced, retrieval noise is reduced and the risk of an overfitting is minimized by applying the stepwise model selection to our forward model.

The retrieval approach has also been applied to spectra acquired by GOME- 2 and SCIAMACHY. Thus, we were able to present a continuous SIF data set covering the 08/200203/2012 time period using SCIAMACHY data and the 20072011 time span using GOME-2 data. The number of selected PCs and total model parameters for the GOME-2 data is in line with the expectation from the sensitivity analysis while twice as many PCs (on average 14) are employed for SCIAMACHY data. Nevertheless, our approach suggests using a significantly smaller number of PCs compared to Joiner et al. $(2013,2014)$.

Although the achievable spatial resolution of SIF maps from SCIAMACHY data is coarser than from GOME-2, there is now a decade long continuous SIF time series available. However, a significant discrepancy in absolute SIF values arises when comparing our retrieval results with the V25 results from Joiner et al. (2014), although spatiotemporal pat- terns are similar. A detailed comparison of the V25 algorithm with our algorithm using simulated data might explain the discrepancy, but that is beyond the scope of this work. It remains exceedingly difficult at present to judge which values are more accurate. Despite this issue, a comparison to GOSAT SIF data obtained by Köhler et al. (2015) showed an enhanced correlation for long-term averages between the different retrieval types, evaluated wavelength and satellite instruments for the presented approach. This allows us to conclude that progress has been achieved but also that there is still research to be done. In particular, there is a need for ground-based validation, ideally in areas with relatively homogeneous vegetation.

Furthermore, it must be considered that the SAA causes high uncertainties in large parts of the South American continent when using GOME-2 data. In contrast, a significant impact of the SAA on SCIAMACHY data has not been found. The analysis of different training sets revealed that there is a slight zero level offset in GOME-2 SIF retrievals which is probably related to an instrumental issue. On the basis of the GOME-2 SIF data set in 2009, we have shown that the retrieval is only moderately affected by cloud contamination. It has essentially been found that the SIF signal decreases with an increasing cloud fraction, but the seasonality is maintained.

Finally, it has to be noted that the flexibility of the retrieval method makes it also applicable to other instruments with a similar spectral and radiometric performance as GOME2 and SCIAMACHY, such as the upcoming TROPOMI (Veefkind et al., 2012) on board the Sentinel-5 Precursor and the Earth Explorer 8 mission candidates FLEX (Rascher et al., 2008) and CarbonSat (Bovensmann et al., 2010).

Acknowledgements. The research is funded by the Emmy Noether Programme of the German Research Foundation. With thanks to EUMETSAT to make the GOME-2 data available and ESA for providing the SCIAMACHY data. Jochem Verrelst and Luis Alonso from the University of Valencia are gratefully thanked for the reflectance and fluorescence simulations produced in the framework of the ESA FLUSS project.

Edited by: B. Kahn

\section{References}

Bovensmann, H., Burrows, J., Buchwitz, M., Frerick, J., Noël, S., Rozanov, V., Chance, K., and Goede, A.: SCIAMACHY: mission objectives and measurement modes, J. Atmos. Sci., 56, 127-150, 1999.

Bovensmann, H., Buchwitz, M., Burrows, J. P., Reuter, M., Krings, T., Gerilowski, K., Schneising, O., Heymann, J., Tretner, A., and Erzinger, J.: A remote sensing technique for global monitoring of power plant $\mathrm{CO}_{2}$ emissions from space and related applications, Atmos. Meas. Tech., 3, 781-811, doi:10.5194/amt-3-781-2010, 2010 . 
Chance, K. and Kurucz, R.: An improved high-resolution solar reference spectrum for Earth's atmosphere measurements in the ultraviolet, visible, and near infrared, J. Quant. Spectrosc. Ra., 111, 1289-1295, doi:10.1016/j.jqsrt.2010.01.036, 2010.

Dee, D. P., Uppala, S. M., Simmons, A. J.,Berrisford, P., Poli, P.,Kobayashi, S.,Andrae, U., Balmaseda, M. A., Balsamo, G., Bauer, P., Bechtold, P., Beljaars, A. C. M., van de Berg, L., Bidlot, J., Bormann, N., Delsol, C.,Dragani, R., Fuentes, M., Geer, A. J., Haimberger, L., Healy, S. B., Hersbach, H., Hólm, E. V., Isaksen, L., Kållberg, P., Köhler, M., Matricardi, M., McNally, A. P., Monge-Sanz, B. M., Morcrette, J.-J., Park, B.-K., Peubey, C., de Rosnay, P., Tavolato, C., Thépaut, J.N., and Vitart, F.: The ERA-Interim reanalysis: configuration and performance of the data assimilation system, Q. J. Roy. Meteor. Soc., 137, 553-597, doi:10.1002/qj.828, 2011.

Fell, F. and Fischer, J.: Numerical simulation of the light field in the atmosphere-ocean system using the matrix-operator method, J. Quant. Spectrosc. Ra., 69, 351-388, doi:10.1016/S00224073(00)00089-3, 2001.

Frankenberg, C., Butz, A., and Toon, G. C.: Disentangling chlorophyll fluorescence from atmospheric scattering effects in $\mathrm{O}_{2}$ A-band spectra of reflected sun-light, Geophys. Res. Lett., 38, L03801, doi:10.1029/2010GL045896, 2011a.

Frankenberg, C., Fisher, J. B., Worden, J., Badgley, G., Saatchi, S. S., Lee, J., Toon, G. C., Butz, A., Jung, M., Kuze, A., and Yokota, T.: New global observations of the terrestrial carbon cycle from GOSAT: Patterns of plant fluorescence with gross primary productivity, Geophys. Res. Lett., 38, L17706, doi:10.1029/2011GL048738, 2011b.

Frankenberg, C., O’Dell, C., Guanter, L., and McDuffie, J.: Remote sensing of near-infrared chlorophyll fluorescence from space in scattering atmospheres: implications for its retrieval and interferences with atmospheric $\mathrm{CO}_{2}$ retrievals, Atmos. Meas. Tech., 5, 2081-2094, doi:10.5194/amt-5-2081-2012, 2012.

Friedl, M. A., McIver, D. K., Hodges, J. C. F., Zhang, X., Muchoney, D., Strahler, A. H., Woodcock, C. E., Gopal, S., Schneider, A., Cooper, A., Baccini, A.,Gao, F., and Schaaf, C.: Global land cover mapping from MODIS: algorithms and early results, Remote Sens. Environ., 83, 287-302, 2002.

Govaerts, Y. M., Wagner, S., Lattanzio, A., and Watts, P. : Joint retrieval of surface reflectance and aerosol optical depth from MSG/SEVIRI observations with an optimal estimation approach: 1. Theory, J. Geophys. Res.-Atmos., 115, D02203, doi:10.1029/2009JD011779, 2010.

Guanter, L., Frankenberg, C., Dudhia, A., Lewis, P., GómezDans, J., Kuze, A., Suto, H., and Grainger, R. G.: Retrieval and global assessment of terrestrial chlorophyll fluorescence from GOSAT space measurements, Remote Sens. Environ., 121, 236251, doi:10.1016/j.rse.2012.02.006, 2012.

Guanter, L., Rossini, M., Colombo, R., Meroni, M., Frankenberg, C., Lee, J., and Joiner, J.: Using field spectroscopy to assess the potential of statistical approaches for the retrieval of suninduced chlorophyll fluorescence from ground and space, Remote Sens. Environ., 133, 52-61, doi:10.1016/j.rse.2013.01.017, 2013.

Guanter, L., Zhang, Y., Jung, M., Joiner, J., Voigt, M., Berry, J. A., Frankenberg, C., Huete, A. R., Zarco-Tejada, P., Lee, J.,Moran, M., Ponce-Campos, G., Beer, C., CampsValls, G., Buchmann, N., Gianelle, D., Klumpp, K., Cescatti, A.,
Baker, J., and Griffis, T.: Global and time-resolved monitoring of crop photosynthesis with chlorophyll fluorescence, P. Natl. Acad. Sci. USA, 111, E1327-E1333, 2014a.

Guanter, L., Aben, I., Tol, P., Krijger, M., Hollstein, A., Köhler, P., Damm, A., Frankenberg, C., and Joiner, J.: Potential of the TROPOspheric Monitoring Instrument (TROPOMI) onboard the Sentinel-5 Precursor for the monitoring of terrestrial chlorophyll fluorescence, Atmos. Meas. Tech., 8, 1337-1352, doi:10.5194/amt-8-1337-2015, 2015.

Joiner, J., Yoshida, Y., Vasilkov, A. P., Yoshida, Y., Corp, L. A., and Middleton, E. M.: First observations of global and seasonal terrestrial chlorophyll fluorescence from space, Biogeosciences, 8, 637-651, doi:10.5194/bg-8-637-2011, 2011.

Joiner, J., Yoshida, Y., Vasilkov, A. P., Middleton, E. M., Campbell, P. K. E., Yoshida, Y., Kuze, A., and Corp, L. A.: Filling-in of near-infrared solar lines by terrestrial fluorescence and other geophysical effects: simulations and space-based observations from SCIAMACHY and GOSAT, Atmos. Meas. Tech., 5, 809-829, doi:10.5194/amt-5-809-2012, 2012.

Joiner, J., Guanter, L., Lindstrot, R., Voigt, M., Vasilkov, A. P., Middleton, E. M., Huemmrich, K. F., Yoshida, Y., and Frankenberg, C.: Global monitoring of terrestrial chlorophyll fluorescence from moderate-spectral-resolution near-infrared satellite measurements: methodology, simulations, and application to GOME-2, Atmos. Meas. Tech., 6, 2803-2823, doi:10.5194/amt6-2803-2013, 2013.

Joiner, J., Yoshida, Y., Vasilkov, A. P., Schaefer, K., Jung, M., Guanter, L., Zhang, Y., Garrity, S., Middleton, E. M., Huemmrich, K. F., Gu, L., and Belelli Marchesini, L.: The seasonal cycle of satellite chlorophyll fluorescence observations and its relationship to vegetation phenology and ecosystem atmosphere carbon exchange, Remote Sens. Environ., 152, 375-391, doi:10.1016/j.rse.2014.06.022, 2014.

Köhler, P., Guanter, L., and Frankenberg, C: Simplified physicallybased retrieval of sun-induced chlorophyll fluorescence from GOSAT data, Geosci. Remote Sens. Lett., 99, 1-5, doi:10.1109/LGRS.2015.2407051, 2015.

Lichtenberg, G., Kleipool, Q., Krijger, J. M., van Soest, G., van Hees, R., Tilstra, L. G., Acarreta, J. R., Aben, I., Ahlers, B., Bovensmann, H., Chance, K., Gloudemans, A. M. S., Hoogeveen, R. W. M., Jongma, R. T. N., Noël, S., Piters, A., Schrijver, H., Schrijvers, C., Sioris, C. E., Skupin, J., Slijkhuis, S., Stammes, P., and Wuttke, M.: SCIAMACHY Level 1 data: calibration concept and in-flight calibration, Atmos. Chem. Phys., 6, 5347-5367, doi:10.5194/acp-6-5347-2006, 2006.

Meroni, M., Rossini, M., Guanter, L., Alonso, L., Rascher, U., Colombo, R., and Moreno, J.: Remote sensing of solarinduced chlorophyll fluorescence: review of methods and applications, Remote Sens. Environ., 113, 2037-2051, doi:10.1016/j.rse.2009.05.003, 2009.

Munro, R., Eisinger, M., Anderson, C., Callies, J., Corpaccioli, E., Lang, R., Lefebvre, A., Livschitz, Y., and Pérez Albiñana, A.: GOME-2 on MetOp, in: Atmospheric Science Conference, ESA Special Publication, 628, 2006.

Rascher, U., Gioli, B., and Miglietta, F.: FLEX - Fluorescence Explorer: A Remote Sensing Approach to Quantify Spatio-Temporal Variations of Photosynthetic Efficiency from Space, Photosynthesis, Energy from the Sun, 1387-1390, doi:10.1007/978-1-4020-6709-9_299, 2008. 
Sanders, A. F. J. and de Haan, J. F.: Retrieval of aerosol parameters from the oxygen A band in the presence of chlorophyll fluorescence, Atmos. Meas. Tech., 6, 2725-2740, doi:10.5194/amt-62725-2013, 2013.

Veefkind, J. P., Aben, I., McMullan, K., Förster, H., de Vries, J., Otter, G., Claas, J., Eskes, H. J., de Haan, J. F., Kleipool, Q., van Weele, M., Hasekamp, O., Hoogeveen, R., Landgraf, J., Snel, R., Tol, P., Ingmann, P., Voors , R., Kruizinga, B., Vink, R., Visser, H., and Levelt, P. F.: $\{$ TROPOMI\} on the $\{\mathrm{ESA}\}$ Sentinel-5 Precursor: A \{GMES $\}$ mission for global observations of the atmospheric composition for climate, air quality and ozone layer applications, Remote Sens. Environ., 120, 70-83, doi:10.1016/j.rse.2011.09.027, 2012.
Verhoef, W. and Bach, H. : Simulation of hyperspectral and directional radiance images using coupled biophysical and atmospheric radiative transfer models, Remote Sens. Environ., 78, 23 41, doi:10.1016/S0034-4257(03)00143-3, 2003.

Wang, P., Stammes, P., van der A, R., Pinardi, G., and van Roozendael, M.: FRESCO+: an improved $\mathrm{O}_{2}$ A-band cloud retrieval algorithm for tropospheric trace gas retrievals, Atmos. Chem. Phys., 8, 6565-6576, doi:10.5194/acp-8-6565-2008, 2008.

Wit, E., van den Heuvel, E., and Romeijn, J.-W.: All models are wrong...: an introduction to model uncertainty, Statistica Neerlandica, 66, 217-236, doi:10.1111/j.1467-9574.2012.00530.x, 2012.

Zarco-Tejada, P., Pushnik, J., Dobrowski, S., and Ustin, S.: Steadystate chlorophyll a fluorescence detection from canopy derivative reflectance and double-peak red-edge effects, Remote Sens. Environ., 84, 283-294, doi:10.1016/S0034-4257(02)00113-X, 2003. 